\title{
Oxidative stress and impaired oligodendrocyte precursor cell differentiation in neurological disorders
}

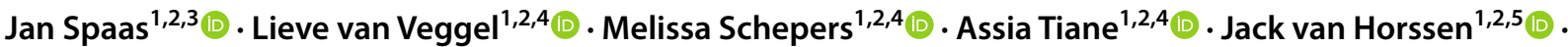 \\ David M. Wilson III ${ }^{2}$. Pablo R. Moya ${ }^{6}$ (I) . Elisabeth Piccart ${ }^{1,2} \cdot$ Niels Hellings $^{1,2}$ (I) $\cdot$ Bert O. Eijnde ${ }^{1,2,7}$ (1) \\ Wim Derave ${ }^{3}$ (1) Rudy Schreiber ${ }^{4}$ Tim Vanmierlo ${ }^{1,2,4}$ (])
}

Received: 20 October 2020 / Revised: 12 February 2021 / Accepted: 24 February 2021 / Published online: 10 March 2021

(c) The Author(s) 2021

\begin{abstract}
Oligodendrocyte precursor cells (OPCs) account for 5\% of the resident parenchymal central nervous system glial cells. OPCs are not only a back-up for the loss of oligodendrocytes that occurs due to brain injury or inflammation-induced demyelination (remyelination) but are also pivotal in plastic processes such as learning and memory (adaptive myelination). OPC differentiation into mature myelinating oligodendrocytes is controlled by a complex transcriptional network and depends on high metabolic and mitochondrial demand. Mounting evidence shows that OPC dysfunction, culminating in the lack of OPC differentiation, mediates the progression of neurodegenerative disorders such as multiple sclerosis, Alzheimer's disease and Parkinson's disease. Importantly, neurodegeneration is characterised by oxidative and carbonyl stress, which may primarily affect OPC plasticity due to the high metabolic demand and a limited antioxidant capacity associated with this cell type. The underlying mechanisms of how oxidative/carbonyl stress disrupt OPC differentiation remain enigmatic and a focus of current research efforts. This review proposes a role for oxidative/carbonyl stress in interfering with the transcriptional and metabolic changes required for OPC differentiation. In particular, oligodendrocyte (epi)genetics, cellular defence and repair responses, mitochondrial signalling and respiration, and lipid metabolism represent key mechanisms how oxidative/carbonyl stress may hamper OPC differentiation in neurodegenerative disorders. Understanding how oxidative/carbonyl stress impacts OPC function may pave the way for future OPC-targeted treatment strategies in neurodegenerative disorders.
\end{abstract}

Keywords Oligodendrocyte precursor cell $\cdot$ Oxidative stress $\cdot$ Carbonyl stress $\cdot$ Neurodegeneration $\cdot$ Myelination

Jan Spaas and Lieve van Veggel have contributed equally.

Tim Vanmierlo

tim.vanmierlo@uhasselt.be

University MS Center (UMSC), Hasselt-Pelt, Belgium

2 BIOMED Biomedical Research Institute, Faculty of Medicine and Life Sciences, Hasselt University, Hasselt, Belgium

3 Department of Movement and Sports Sciences, Faculty of Medicine and Health Sciences, Ghent University, Ghent, Belgium

4 Department Psychiatry and Neuropsychology, Division of Translational Neuroscience, European Graduate School of Neuroscience, School for Mental Health and Neuroscience, Maastricht University, Maastricht, The Netherlands
5 Department of Molecular Cell Biology and Immunology, Amsterdam Neuroscience, MS Center Amsterdam, Amsterdam University Medical Center, Location VUmc, Amsterdam, The Netherlands

6 Facultad de Ciencias, Instituto de Fisiología, Centro Interdisciplinario de Neurociencia de Valparaíso (CINV), Universidad de Valparaíso, Valparaíso, Chile

7 Faculty of Medicine and Life Sciences, SMRC-Sportsmedical Research Center, BIOMED Biomedical Research Institute, Hasselt University, Diepenbeek, Belgium 


\section{OPCs in health and disease}

Upon differentiation-inducing stimuli, oligodendrocyte precursor cells (OPCs) provide the source of newly born oligodendrocytes for the myelination of neuronal axons in the central nervous system (CNS). OPCs first arise from neural stem cells during the embryonic developmental stage and persist into adulthood, constituting a significant portion $(\sim 5-10 \%$ of glial cells $)$ of the adult CNS [1-4]. OPCs remain by far the most proliferative cell type in the CNS $[5,6]$ and contribute to the maintenance of myelination via low-rate oligodendrocyte turnover [7-9]. OPC differentiation in the adult CNS also drives 'adaptive myelination' during learning and memory. Indeed, myelin plasticity is increasingly being acknowledged as vital, alongside the more generally known synaptic plasticity [10]. Several studies have highlighted that newly formed myelin is essential for implicit motor skill learning [11], explicit learning, and remote (but not recent) memory consolidation and/or recall $[2,8,12-14]$. This evolving position opposes the classic view of OPCs and oligodendrocytes as being passive static insulators around neuronal axons, instead portraying them as dynamic cells that fine-tune neuronal networks and functionally affect behaviour, cognition and neurophysiology [15]. Moreover, OPCs actively survey their environment and quickly initiate repair processes following demyelination. During a process called remyelination, OPCs migrate towards the lesion site, differentiate into mature oligodendrocytes and enwrap surviving axons [16, 17]. Remyelination has been observed in a variety of traumatic and non-traumatic CNS disorders, aiming to protect denuded axons from degeneration and restore normal neuronal conduction $[16,18]$.

When compromised, however, impaired OPC function and (re)myelination appear to play a major role in a variety of neurodegenerative disorders [19]. Inflammation, excitotoxicity, oxidative stress, and protein aggregation are some of the major causes of oligodendrocyte pathology in multiple sclerosis (MS), Alzheimer's disease (AD) or Parkinson's disease (PD), as well as neuropsychiatric disorders such as schizophrenia and major depressive disorder (MDD) [19-25]. Progressive oligodendrocyte abnormalities and eventually oligodendrocyte loss strongly correlate with cognitive decline in the normal ageing brain, AD and MS [26]. Upon oligodendrocyte loss, OPC differentiation is paramount to generate new oligodendrocytes. However, a lack of OPC differentiation impedes CNS (re) myelination, a process that may be more abundant and accurate when performed by newly generated compared to surviving oligodendrocytes [27]. Even in chronically demyelinated MS lesions, the OPC pool is not depleted $[21,28]$. Yet, remyelination is limited and mistargeted [27,
29], and it was estimated that surviving (but not newly generated) oligodendrocytes were the main contributors to remyelination in MS shadow plaques [30]. In schizophrenia and PD, an increase in the OPC population has even been observed in the prefrontal cortex and cerebellum, respectively $[19,31]$.

The reduced differentiation and (re)myelination capacity of aged OPCs appears to be further compromised in neurodegenerative disorders [32-35]. In schizophrenia, various signalling pathways are impaired, with cell division pathways upregulated (e.g. PDGF signalling) but differentiation markers downregulated (e.g. OLIG2) [19]. Disruption of brain connectivity in adolescents with schizophrenia has been linked to impaired OPC differentiation and prefrontal cortex myelination [36]. Similarly, dysregulation of the gene expression network in OPCs is strongly associated with $\mathrm{AD}$ [21, 37]. A recent study analysed RNA expression profiles of autopsy brain tissue from dementia patients and revealed disturbed signalling pathways involved in OPC differentiation, oligodendrocyte development, gliogenesis, myelination and axon ensheathment [38]. Disruption of signalling pathways involved in differentiation and migration of OPCs, such as PDGF-2A and FGF-2, is also observed in MS, eventually leading to a differentiation block in the more chronic stage [39]. In addition, OPC differentiation is inhibited by extracellular myelin debris derived from damaged oligodendrocytes [40]. Even in amyotrophic lateral sclerosis (ALS), comparable fate restriction of OPCs is observed, limiting repair and consequently resulting in loss of oligodendrocyte support in the brain [21, 41].

In summary, the evidence is emerging that OPC abnormalities are an important pathological hallmark in the development and/or progression of several neurodegenerative (and psychiatric) disorders. Several questions, however, remain: what are the mechanisms that give rise to OPC dysfunction? How (much) does this dysfunction affect (re)myelination and ultimately the neurophysiological and functional outcomes? At what disease stage and in what cellular environments can OPC dysfunction be effectively targeted therapeutically? In the present review, we focus on the effect of elevated oxidative stress, a common physiological phenomenon observed in ageing, neuroinflammation and neurodegeneration, on OPC differentiation. We begin by describing the transcriptional and metabolic changes required for oligodendrocyte development. Next, the physiology and sources of oxidative stress are discussed, followed by the inherent vulnerability of OPCs to oxidative stress and the effect of oxidative stress on OPC differentiation. We then discuss (epi)genetic and metabolic mechanisms that may be affected by oxidative stress in OPCs and interfere with cell differentiation/myelination. Finally, we highlight potential therapeutic approaches to tackle oxidative stress-induced OPC dysfunction and maintain myelin plasticity in neurodegenerative disease. 


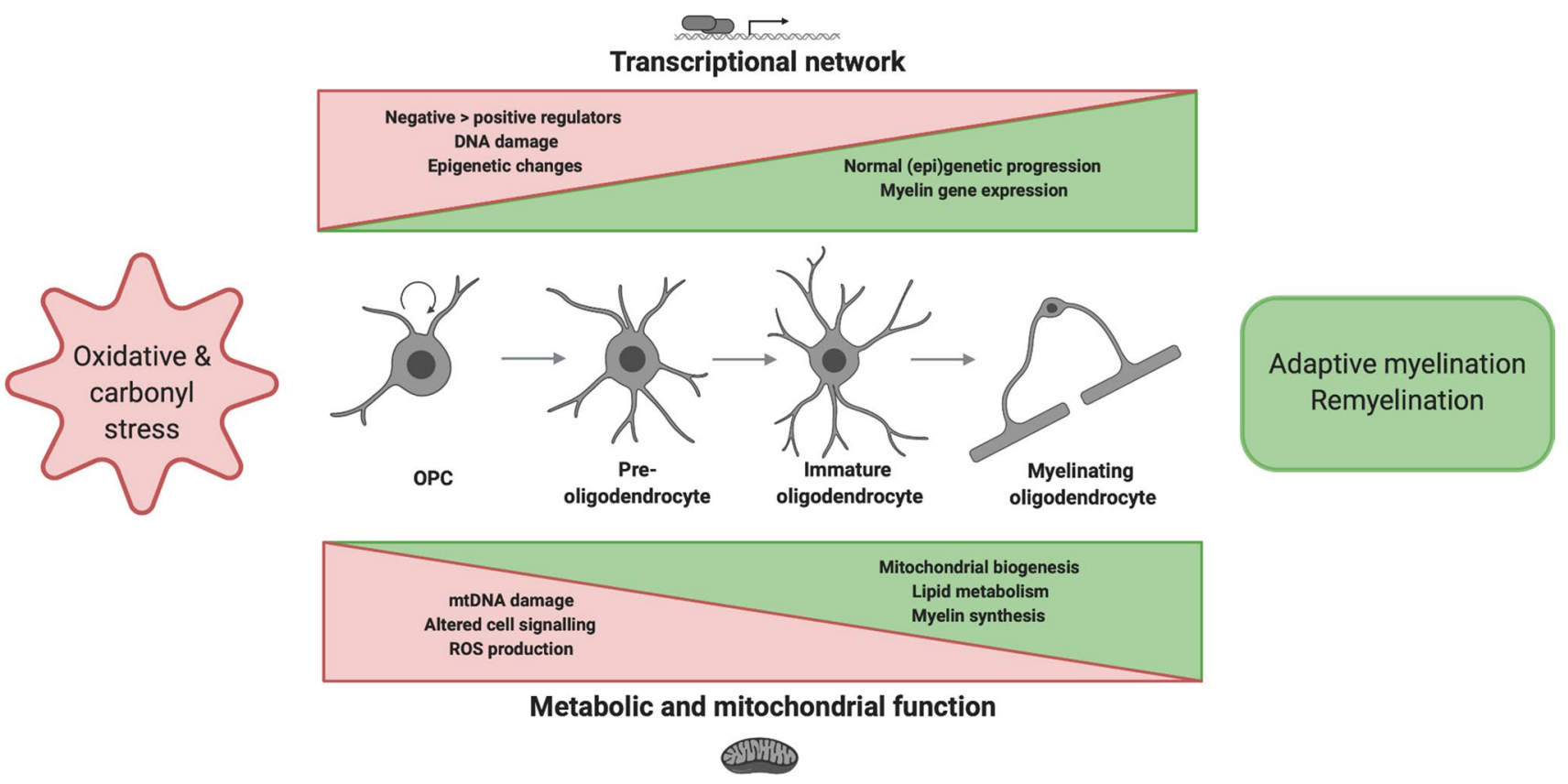

Fig. 1 Outline of the review describing oxidative and carbonyl stress during transcriptional and metabolic changes associated with OPC differentiation. OPC differentiation occurs in at least four different stages characterised by increasing morphological complexity. By altering normal transcriptional and metabolic adaptations required for

A graphical abstract-style summary of the review topic can be found in Fig. 1.

\section{From OPC to oligodendrocyte}

Normal oligodendrocyte development and myelination are controlled by a complex transcriptional network and require a substantial metabolic demand.

\section{Transcriptional network for OPC differentiation}

Both neonatal and adult oligodendrogenesis comprises at least four distinct stages (Fig. 1) based on cell morphology and expression of specific markers. Due to tightly controlled changes in the transcriptional network, small bipolar $\mathrm{A} 2 \mathrm{B5}^{+} / \mathrm{NG}^{+} / \mathrm{PDGF} \mathrm{R}^{+}$OPCs are able to transform into branched axon wrapping $\mathrm{GalC}^{+} / \mathrm{MBP}^{+} / \mathrm{PLP}^{+}$oligodendrocytes [42]. Advanced gene knockout studies, singlecell sequencing and bioinformatics analyses have yielded important insights into positive and negative regulators of oligodendrocyte lineage development. The most wellestablished positive regulators are the OLIG1, OLIG2 and SOX10 transcription factors that are expressed throughout all developmental stages $[43,44]$. Other transcription factors that operate as positive differentiation regulators are expressed predominantly in the early stage (e.g. ASCL1), differentiation, oxidative/carbonyl stress may hamper oligodendrocyte development and consequently (re)myelination. $O P C$ oligodendrocyte precursor cell; ROS reactive oxygen species. Figure created in BioRender

the late stage (e.g. NKX6.2) or biphasically (e.g. NKX2.2) [45]. Terminal oligodendrocyte differentiation requires activation of the myelination program, a process where myelin regulatory factor (MYRF) plays a pivotal role [46]. According to the 'de-repression' model of oligodendrocyte development, differentiation-enhancing transcription factors are initially countered by several negative regulators including ID2, ID4, HES5, SOX5, SOX6 and TCF4 [47-49]. Interestingly, reciprocal interactions between NKX2.2, OLIG2 and SOX10 have been described [50], as well as between MYRF and SOX10 [51, 52]. Hence, oligodendrocyte development reflects a complex interplay between many spatiotemporally orchestrated signals, rather than a simple positive/negative net sum.

Maintaining the transcriptomic homeostasis is a significant challenge for developing oligodendrocytes, influenced by divergent intra- and extracellular cues that act to either inhibit or facilitate OPC differentiation (e.g. growth factors) [48]. Increasing evidence also supports that epigenetic modulation of the transcriptional network-including histone modifications, DNA methylation and microRNAs (miRNAs)_-governs oligodendrocyte development [53, 54]. These epigenetic mechanisms can control the activation and repression of differentiation signals in OPCs; when dysregulated, normal oligodendrocyte development is blocked. 


\section{Metabolic and mitochondrial adaptations during differentiation}

Oligodendrocytes can accommodate up to 40 myelin segments and maintain membrane extensions up to $100 \times$ the weight of its cell body $[3,55]$, with immature oligodendrocytes undergoing as much as 6,500-fold increases in membrane area $[56,57]$. The myelin sheath is a lipid-rich membrane built from phospholipids $(\sim 40 \%)$, glycolipids $(\sim 20 \%)$ and cholesterol ( $40 \%$, which is $80 \%$ of the total brain cholesterol pool) [58-60], and serves as an insulating layer around nerves that transmits electrical signals within the CNS.

Driven by (epi)genetic regulation at the nuclear and mitochondrial DNA (nDNA, mtDNA) levels, OPC differentiation and myelination go hand in hand with several metabolic adaptations. In vitro rodent and human oligodendrocyte differentiation induced many transcripts related to mitochondrial biogenesis, electron transport chain (ETC), ATP synthesis, fatty acid oxidation and cholesterol biosynthesis [61]. Moreover, the total mtDNA content increased relative to nDNA up to fourfold. Recent quantitative proteomic analysis confirmed the upregulation of multiple metabolic processes related to lipid synthesis, myelination, and cytoskeletal organisation [62]. Nevertheless, cellular metabolism, mitochondrial respiration, and cell signalling pathways in (developing) oligodendrocytes remain understudied compared to neurons. Rinholm et al. were the first to characterise mitochondrial location, morphology and movement within oligodendrocytes [63]. Mitochondria were detected in cell somata, primary processes and cytoplasmic channels of the myelin sheath, with lower mitochondrial density in the myelin sheath compared to the primary processes. Mitochondria were able to move in and out of the myelin sheaths and primary processes, albeit with lower mobility and slower speed than in neurons. A similar examination of mitochondria in OPCs or developing oligodendrocytes is lacking to date; however, an increase in the number of mitochondria in rat oligodendrocyte processes was observed following differentiation in vitro [64].

In oligodendrocytes, mitochondria are not only needed for cellular energy provision (ATP synthesis by oxidative phosphorylation), but also for lipid biosynthesis to produce myelin [58, 65]. In fact, based on their morphological properties (i.e. short length, few cristae), it has been suggested that oligodendrocyte mitochondria synthesise relatively little ATP [63]. Instead, acetyl coenzyme A (acetyl-CoA) produced in the mitochondrial matrix can be transported out of the mitochondria as citrate [61]. Acetyl-CoA is an important substrate in fatty acid or cholesterol synthesis that are central to myelin sheath formation via conversion by acetyl-CoA carboxylase (ACC) and fatty acid synthase (FASN) or 3-hydroxy-3-methylglutaryl-CoA synthase 1
(HMGCS1) and HMG-CoA reductase (HMGCR), respectively. Although acetyl-CoA is a key molecule found at the crossroads of cellular lipid biosynthesis and energy generation in oligodendrocytes, the relative proportion of acetylCoA derived from glucose/pyruvate, lactate or $\beta$-oxidation for these processes remains unclear [58, 66, 67]. Mitochondrial $\beta$-oxidation is assisted by peroxisomal $\beta$-oxidation that generates acetyl-CoA via breakdown of (very) long-chain fatty acids (VLCFA) [68, 69].

A healthy metabolic function is indispensable for oligodendrocytes during all stages of differentiation. The late developmental stages require extensive biosynthesis and maintenance of myelin membranes. Yet, higher in vitro ATP production and oxygen consumption rates per $\mu \mathrm{g}$ protein have been reported in OPCs compared to oligodendrocytes, highlighting that OPC differentiation is an energy-demanding process [70]. The metabolic burden of myelinating glia is tightly coupled to axonal metabolism. Once oligodendrocytes have ensheathed neuronal axons they can shuttle lactate/pyruvate via the MCT1 monocarboxylate transporter $[59,71,72]$. In addition, it was recently demonstrated that axons with thinner myelin sheaths had larger axonal mitochondria, further underscoring the importance of oligodendrocytes for neuronal health [73].

\section{Oxidative and carbonyl stress in OPC differentiation}

\section{Physiology and sources of oxidative/nitrosative and carbonyl stress in OPCs}

Oxidative stress results from a failure to control cellular pro$v s$. anti-oxidant levels. The most well-known pro-oxidants are reactive oxygen and nitrogen species (ROS and RNS, respectively), a group of small molecules encompassing both free radical and non-radical derivatives of oxygen and nitrogen. Free radicals such as superoxide $\left(\mathrm{O}_{2}{ }^{-}\right)$and nitric oxide $\left(\mathrm{NO}^{\circ}\right)$ are atoms or molecules that possess at least one unpaired electron on the valence shell and are extremely reactive with short half-lives. The generally more stable non-radical species (e.g. hydrogen peroxide, $\mathrm{H}_{2} \mathrm{O}_{2}$ ) can exert similar biological effects and can emerge from or be converted to radical species in the presence of transition metals (Fig. 2).

OPCs are exposed to ROS generated intra- and extracellularly. Intracellularly, approximately $0.2-2 \%$ of electrons that pass through the electron transport chain (ETC) leak and interact with oxygen to form $\mathrm{O}_{2}{ }^{-}$that is released into the mitochondrial matrix (complex I) or the intermembrane space (complex III) [74-76]. Under conditions of high energy demand or mitochondrial dysfunction, increased amounts of ROS are produced. In CNS disorders, 


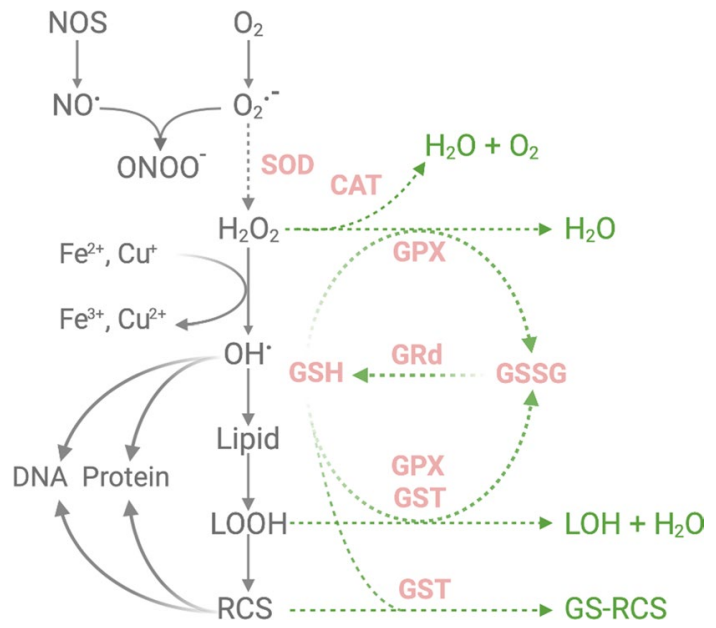

Fig. 2 ROS generation and antioxidant defence in OPCs. The primary production and conversion pathways of ROS/RCS are shown on the left. The green arrows illustrate major antioxidant and detoxifying pathways. Enzymes and molecules with a known reduction in activity and/or expression in OPCs compared to mature oligodendrocytes and/or other CNS cell types are depicted in pink and with dotted lines. $C A T$ catalase, $\mathrm{Cu}$ Copper, $\mathrm{Fe}$ Iron, $G P X$ glutathione peroxidase, GRd glutathione reductase, GSH glutathione, GSSG glutathione disulphide, GST glutathione S-transferase, $\mathrm{H}_{2} \mathrm{O}_{2}$ hydrogen peroxide, $\mathrm{LOH}$ : lipid alcohol, $\mathrm{LOOH}$ lipid hydroperoxides, $N O S$ nitric oxide synthase, $\mathrm{NO}^{\bullet}$ nitric oxide, $\mathrm{O}_{2}$ oxygen, $\mathrm{O}_{2}{ }^{\bullet-}$ superoxide, $\mathrm{ONOO}^{-}$peroxynitrite, $\mathrm{OH}$ hydroxyl radical, $R C S$ reactive carbonyl species, $S O D$ superoxide dismutase. Figure created in BioRender

mitochondrial dysfunction has mainly been described in neurons $[77,78]$ and even in relation to myelin thickness [73], but less is known about oligodendrocytes or OPCs. Studies on non-mitochondrial intracellular ROS/RNS sources in OPCs and oligodendrocytes are also limited, but include inducible nitric oxide synthase (iNOS), neuronal NOS (nNOS) [79-81] and NADPH oxidase (NOX) enzymes [82, 83], as well as peroxisomal lipid metabolism [84]. In vitro studies have shown mitochondrial or enzymatic ROS production in OPCs/oligodendrocytes upon exposure to a variety of stimuli, such as proinflammatory cytokines [85, 86], VLCFA [84] and oxygen-glucose deprivation [87-89]. OPCs express ionotropic glutamate receptors (AMPARs, KARs, NMDARs) and metabotropic glutamate receptors (mGluRs), and can receive synaptic input from over a hundred neurons; however, these synapses are lost as OPCs mature into oligodendrocytes [90, 91]. Sustained activation of either AMPA or kainate receptors in oligodendrocytes causes a harmful increase of cytosolic $\mathrm{Ca}^{2+}$, which results in mitochondrial depolarization, an increase in ROS and, consequently, cell death [87, 92-94]. However, it should be noted that under physiological conditions, AMPA receptors are activated for mere milliseconds. Activation of NMDA receptors stimulates protein kinase $\mathrm{C}$ (PKC), which in its turn activates NOX2 and generates ROS [95]. Group I
mGluRs, on the other hand, can attenuate the excitotoxicity and ROS accumulation that results from overactivation of ionic glutamate receptors [87, 96]. Clearly, mitochondria play a key role in these processes, by acting as a buffer organelle for $\mathrm{Ca}^{2+}$ and $\mathrm{Fe}$-ions [97-99] that is directly linked to redox metabolism and cell signalling. Hereby, mitochondrial redox state is a powerful regulator of gene transcription, protein translation machinery and cell growth, but also apoptosis (e.g. via opening of mitochondrial permeability transition pore) $[100,101]$. Interestingly, greater mitochondrial activity, resulting in higher ROS generation and thereby the risk of oxidative injury, has been observed in neurological disorders such as MS [101-103]. So far, this has predominantly been reported in axons as a result of demyelination, but it would be interesting to also assess this in OPCs and oligodendrocytes themselves [101, 102, 104, 105].

Besides the intracellular threats, extracellular ROS released by pro-inflammatory cells, such as microglia and macrophages, can attack neighbouring OPCs/oligodendrocytes [106, 107]. It is important to note that the effect of ROS in circulating or infiltrating immune cells depends on the site of production, especially in case of autoimmunity where ROS induce Treg activation while limiting $\mathrm{T}$ cell proliferation and cytokine production [108-111], resulting in dampened disease activity. Similarly, increased ROS generation by peripheral blood monocytes via NOX3 is associated with better response to dimethyl fumarate in MS patients. Within the CNS parenchyma, however, ROS production is frequently linked to tissue injury [108, 109]. Acute inflammatory activity of microglia and infiltrated macrophages causes an oxidative burst, but chronic low-grade microglia/ astrocyte activation is also a frequent characteristic of neurological disease. For example, high expression of iNOS and NOX complexes 1-5 (mainly NOX2) are the main drivers of oxidative injury in active MS lesions, the prototype of CNS inflammation [112, 113]. Adjacent normal-appearing white matter (NAWM) [114, 115] and macroscopically-invisible preactive lesions [116] also display microglial inflammation and NOX expression, indicating widespread ROS production in MS brain tissue. MDD [117], schizophrenia [118, 119], AD [120, 121], PD [122, 123] and stroke [124] are all characterised by abundant microglial activation and inflammation-mediated oxidative stress. Interestingly, when pro-oxidant levels are elevated in the CNS (by knockout of the antioxidant transcription factor nuclear factor erythroid 2-related factor 2, Nrf2), increased oligodendrocyte damage and demyelination is observed [125]. Alternatively, upregulation of the antioxidant defence system in OPCs rescues them from oxidative stress-induced damage [126-128].

ROS, RNS, and their reaction products (e.g. peroxynitrite, $\mathrm{ONOO}^{-}$) attack all major classes of biomolecules including lipids, DNA, RNA and proteins. The CNS is prone to lipid peroxidation due to abundant membrane poly-unsaturated 
fatty acids (PUFAs), as well as high oxygen consumption and iron levels [129]. The process of lipid peroxidation is initiated by hydrogen abstraction, creating a carbon-centred radical $\left(\mathrm{L}^{\bullet}\right)$. The peroxyl radical $\left(\mathrm{LOO}^{\bullet}\right)$ that is formed following rearrangement and $\mathrm{O}_{2}$ addition is then capable of starting a chain reaction of repetitive hydrogen abstraction from other PUFAs (propagation). Common end products of these reactions, the lipid hydroperoxides $(\mathrm{LOOH})$, are broken down to cytotoxic aldehydes (Fig. 2). Different structural categories of aldehydes include (1) $\alpha, \beta$-unsaturated aldehydes, such as 4-hydroxynonenal (HNE) and acrolein, (2) keto aldehydes, such as methylglyoxal, (3) dialdehydes, such as malondialdehyde and glyoxal [130-135]. These lipidderived aldehydes (or lipid-derived reactive carbonyl species [RCS]) rapidly form adducts with phospholipids, DNA, and His, Cys, Lys and Arg residues on proteins. Although many ROS have a half-life below one second, RCS can last hours or even days and diffuse out of the cell, inciting cell damage and a variety of signalling effects [136-139].

\section{Endogenous defence mechanisms and OPC vulnerability}

The content and activity of enzymatic and non-enzymatic antioxidant defence strategies are limited in oligodendrocytes and in particular in OPCs (Fig. 2). Superoxide dismutase (SOD) is of primary importance for the enzymatic conversion of $\mathrm{O}_{2}{ }^{-}$to $\mathrm{H}_{2} \mathrm{O}_{2}$. Three isoforms of SOD, copper/ zinc-SOD (SOD1) in the cytosol, manganese-SOD (SOD2) in mitochondria, and extracellular SOD (SOD3), have been identified so far [140]. In OPCs, SOD2 protein levels and activity are up to fourfold lower compared to mature oligodendrocytes [128, 141]. In MDD, a further reduction of SOD1 and SOD2 expression in the oligodendrocyte lineage is reported, suggesting even higher vulnerability in a diseased state [142]. $\mathrm{H}_{2} \mathrm{O}_{2}$ is converted by enzymatic antioxidants such as catalase (CAT) and glutathione peroxidases (GPXs). CAT does not play a crucial role at low levels of $\mathrm{H}_{2} \mathrm{O}_{2}$ but becomes more important when these levels increase [143]. GPXs reduce $\mathrm{H}_{2} \mathrm{O}_{2}$ by using glutathione (GSH) as an electron donor. Eight different isoforms of GPX have been identified, with GPX1 being regarded as the most important [144]. Interestingly, GPX1 is also able to neutralise lipid peroxidation products. GPX1 protein levels and activity were found to be 2.5 to threefold higher in mature oligodendrocytes compared to OPCs [145]. CAT appeared largely inactive in OPCs under oxidative stress, a phenotype that was observed after inhibiting GPX1 as well. This latter finding suggests that GPX1 acts not only as the primary peroxidase but also protects CAT activity $[141,145]$.

GSH, a tripeptide synthesised from glutamate, cysteine and glycine, is essential for the functioning of GPXs and can also act on its own (non-enzymatically) [146]. GSH can react with $\mathrm{O}_{2}{ }^{-}$and hydroxyl radical $\left(\mathrm{OH}^{\bullet}\right)$, forming the oxidised derivative glutathione disulphide (GSSG). GSH levels can be regenerated by reducing GSSG with electrons from NADPH, or by de novo synthesis [143]. The GSH/ GSSG ratio is among the most widely used measurements to sense redox alterations. GSH is also able to form adducts with RCS, a reaction that is enhanced by glutathione S-transferases (GST). The GST $\mathrm{G}_{\Pi}$ isoenzyme has been detected as a marker for mature oligodendrocytes that is absent in OPCs [147-149]. Moreover, recent studies identified an additional isoenzyme, GST $\alpha 4$, to do play a role in OPC differentiation and protection against HNE [109]. In line with possessing a threefold lower basal level of GSH compared to astrocytes, OPCs are more vulnerable to GSH depletion [141, 150, 151]. Several oxidative stressors (e.g. $\mathrm{H}_{2} \mathrm{O}_{2}$ ) are known to cause a profound depletion $(\sim 40 \%)$ of GSH in OPCs already at low concentrations $[152,153]$. Other risk factors contributing to the highly vulnerable state of OPCs and (developing) oligodendrocytes are high levels of mitochondrial oxygen consumption, in addition to a greater need than other cells to acquire and retain iron (required for differentiation as well as myelination) [154]. Iron, however, is a catalyst of the Fenton reaction that converts $\mathrm{H}_{2} \mathrm{O}_{2}$ into highly reactive $\mathrm{OH}^{*}$ [140]. This reaction may be particularly relevant to genomic damage, as iron has been shown to directly interact with the negatively charged phosphate backbone of DNA [155].

Considering their high metabolic load and presence of ROS, it is quite striking that OPCs have such limited antioxidant defence mechanisms. Under oxidative stress conditions, cells can increase their enzymatic and nonenzymatic antioxidant protection, most notably via induction of transcription factor Nrf2, which can bind to antioxidant response elements (ARE) in the promotor regions of genes encoding antioxidant proteins [156, 157]. In MS, Nrf2-driven antioxidant enzyme expression in oligodendrocytes is prominent in actively demyelinating lesions but absent in late-stage active lesions, despite ongoing Nrf2 activation in other cells such as astrocytes [158].

Cells of the oligodendrocyte lineage and in particular OPCs could be considered the Achilles heel to oxidative stress in neurodegenerative disorders, especially due to the immense morphological change in a short time window coupled to limited defence mechanisms against stressors. Whereas high levels of oxidised lipids, protein and DNA are often found in different CNS cells, cerebrospinal fluid or plasma, mostly paralleled by reductions in the antioxidant defence, oligodendrocytes and OPCs show the greatest levels of oxidative damage [89,159-164]. The apparent mismatch in production and elimination of ROS/RCS in OPCs and oligodendrocytes warrants future research to fully characterise the source and severity of oxidative/carbonyl stress under different pathological conditions. 


\section{Oxidative stress affects OPC differentiation}

The question of whether and how oxidative stress impacts oligodendrocyte development is relevant to the study of both CNS development and neurological disease since both require OPC differentiation and (re)myelination. During development, OPCs that do not contact an axon undergo apoptosis, probably contributing to region-specific myelination [165-167]. This axon-dependent OPC survival and differentiation is in part mediated by physiological ROS elevations. Indeed, mimicking neuronal activity in vitro by glutamate-mediated NMDA receptor activation induced OPC differentiation via ROS production, an outcome that was similarly inhibited by NOX blockade [94]. A positive effect of ROS on oligodendrocyte development was also shown by Accetta et al., who observed that $\mathrm{H}_{2} \mathrm{O}_{2}$ treatment could enhance the expression of oligodendrocyte markers (OLIG2, MBP) in MO3-13 cells after 1-4 days, in the absence of any other differentiation-boosting stimuli [83]. This effect was dependent on PKC signaling and promoted additional intracellular ROS production by NOX3 and NOX5. Silencing of NOX by siRNAs prevented oligodendrocyte differentiation induced by $\mathrm{H}_{2} \mathrm{O}_{2}$, suggesting that ROS function as intracellular messengers that advance differentiation upon external stimuli.

Yet, it is important to emphasize though that the cellular source, duration and level of ROS dictate the cellular response. Immature oligodendrocytes are considered more vulnerable to several kinds of cytotoxic triggers directly and indirectly related to oxidative stress $[89,141]$. In vitro studies clearly show that physiological but sublethal oxidative stress interferes with OPC differentiation without affecting cell viability, and high levels of ROS can induce OPC death. As discussed previously, extensive OPC cell death does not appear as a major feature in neurodegeneration, suggesting that excessive oxidative stress is not attained. ROS exposure during in vitro OPC differentiation reduces mature oligodendrocyte and myelin markers (e.g. GalC, MBP) and alters the expression of cell differentiation regulators [126, 152]. Gene expression of positive differentiation regulators, including SOX10, SHH and HDAC3, was suppressed after a $72 \mathrm{~h}$ oxidative stress exposure. Conversely, ID2 and ID4, known inhibitors of differentiation, were increased [152]. Likewise, in vivo data shows that oxidative stress hampers myelination during early development and remyelination during (adult) neurological disease [89, 141]. For example, after white matter injury, ROS blocked a compensatory response in oligodendrocyte regeneration and hampered repair, a phenomenon that was paralleled by functional deficits in working memory similar to neurodegenerative disorders [168]. Compared to ROS, less is known about the direct effects of RCS; however, sublethal concentrations of the lipid peroxidation product HNE were reported to inhibit mitogenic and chemotactic responses to PDGF in undifferentiated OPCs [169]. In addition, reducing mitochondrial HNE levels promotes oligodendrocyte survival and differentiation [109].

It is important to note that most in vitro data supporting the vulnerability of OPCs to ROS used normoxic conditions, potentially meaning altered levels of ROS compared to normal CNS homeostasis [170]. However, collectively, it is hypothesised that elevated ROS/RCS levels in neurodegenerative disorders block the ability of OPCs to differentiate, resulting in a limited CNS (re)myelination capacity. If excessive ROS occurs early in disease, OPC function may start to deteriorate long before the chronic phases that are typically associated with impaired remyelination [171].

\section{The interplay between ROS/RCS, (epi) genetics, mitochondria, cell signalling and OPC differentiation}

Despite the evidence that shows a convincing effect of oxidative stress on OPC differentiation, remarkably little research has examined the underlying mechanisms. In this section, we discuss how oxidative/carbonyl stress may interfere with transcriptional and metabolic changes required for OPC differentiation; aiming to guide future research in this area (Fig. 3, Table 1).

\section{Oxidative stress-induced damage to nDNA and $m t D N A$ in OPCs}

Reactive chemicals of oxidative stress can damage all major macromolecules, including DNA. Modifications to DNA can adversely affect the fidelity or operation of many molecular processes such as transcription and replication, and can lead to mutations or genomic instability in OPCs and oligodendrocytes [172]. Similar to neurons, oligodendrocytes and OPCs are known to accumulate DNA damage with age and disease [26]. Aged OPCs, like aged stem cells, show higher levels of oxidative DNA damage than their younger counterparts [33]. OPCs with trauma-induced DNA damage appear to differentiate into oligodendrocytes with a reduced myelination capacity, if they are able to differentiate at all [173]. DNA damage occurs in both nDNA and mtDNA, with the latter being highly vulnerable due to its proximity to the respiratory chain [174]. Below, we touch upon the different mechanisms by which ROS can modify the nuclear and mitochondrial genomes.

Firstly, ROS can attack DNA bases by adding to their double bonds, abstract hydrogen atoms from methyl groups, or attack the sugar residues [175]. Among the DNA bases, guanine $(\mathrm{G})$, which contains a variety of oxidation sites, is the most prone to be attacked by ROS and RCS due to its low reduction potential [176]. The most abundant and 


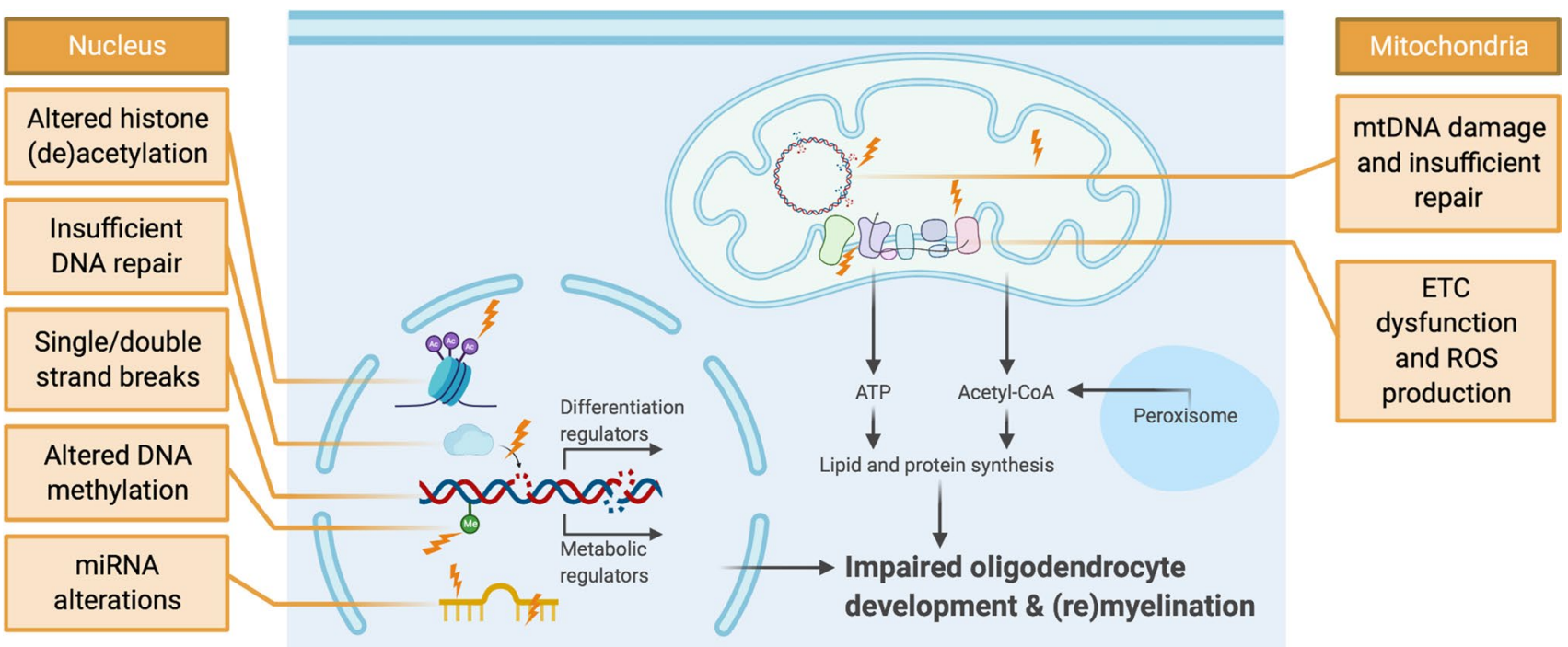

Fig. 3 Putative effect of ROS/RCS on OPC (epi)genetics, mitochondria, cell signalling and cell differentiation. Oxidative stress (lightning bolts) affects many cellular compartments. In OPCs, this can lead to inadequate differentiation and impaired (re)myelination capacity. At the nuclear DNA (nDNA) level, oxidative stress may trigger multiple (epi)genetic alterations in OPCs (shown on the left). In addition, oxidative stress-induced changes in metabolism, mitochondrial function and mitochondrial DNA (mtDNA) may also contribute to the observed differentiation block in neurodegeneration. ETC electron transport chain. Figure created in BioRender

Table 1 Summary of potential mechanisms involved in impaired OPC differentiation linked to oxidative stress

\begin{tabular}{|c|c|c|c|}
\hline Mechanism of interest & Description & Effect of oxidative stress & $\begin{array}{l}\text { Direct } \\
\text { evi- } \\
\text { dence? }\end{array}$ \\
\hline \multirow[t]{2}{*}{ nDNA and mtDNA damage } & Base modifications (8-oxoG) & Increase & + \\
\hline & SSB and DSB & Increase & + \\
\hline \multirow[t]{3}{*}{ DNA repair } & Excision repair (NER, BER) & Higher need & + \\
\hline & Recombinational repair (DSBR) & Higher need & + \\
\hline & Competing demand: differentiation vs. DNA repair & Increase & \pm \\
\hline \multirow[t]{3}{*}{ Epigenetics } & HAT and HDAC balance & Altered & + \\
\hline & Methylation pattern changes & Altered & \pm \\
\hline & MiRNA activity and biogenesis & Altered & \pm \\
\hline \multirow[t]{2}{*}{ Mitochondria } & ETC function & Decrease & \pm \\
\hline & ROS generation & Increase & + \\
\hline Cell signalling & $\begin{array}{l}\text { ROS-sensitive signalling in relation to cell growth, metabolism, differ- } \\
\text { entiation and antioxidant defence (e.g. AMPK, MAPK, PGC-1 } \alpha \text {, Nrf2, } \\
\text { mTOR) }\end{array}$ & Altered & \pm \\
\hline
\end{tabular}

$+=$ direct evidence linking oxidative stress to the mechanism of interest in OPCs, $\pm=$ suggested link but no direct evidence linking oxidative stress to the mechanisms in OPCs yet. 8-oxoG 8-oxo-7,8-dihydroguanine, BER base excision repair, DSB double-strand breaks, $D S B R$ doublestrand break repair, ETC electron transport chain, HAT histone acetyltransferases, HDAC histone deacetylases, NER nucleotide excision repair, $O P C$ oligodendrocyte precursor cell, $R O S$ reactive oxygen species, $S S B$ single-strand breaks

most studied product of ROS-induced DNA damage is 8-oxo-7,8-dihydroguanine (8-oxoG), which is mutagenic. It is important to note that in the presence of normal physiological levels of ROS, a certain level of guanine oxidation may be necessary for normal functioning [177]. In MS and other neurodegenerative disorders, increased ROS levels are linked to increased levels of 8-oxoG, in both mtDNA and nDNA [172]. A recent in vivo study, investigating the vulnerability of oligodendroglia after neurotrauma, revealed that OPCs contain more oxidative DNA damage (8-oxoG) than mature oligodendrocytes or axons. HNE levels also appeared to increase most in OPCs after neurotrauma, implicating oxidative/carbonyl stress in the pathological outcome [163]. 
Secondly, ROS are able to compromise the DNA backbone by introducing primarily single-strand breaks (SSB), but in rare cases, double strand breaks (DSB) [175]. Additionally, when ROS cause SSBs and base modifications in close vicinity of each other ( $20 \mathrm{bp}$ ), these multiple damaged sites, due to their complexity in being resolved, can have profound effects on genome stability and survival. These lesions can, in an attempt to be repaired, be transformed into DSBs when the sugar-phosphate backbone of both strands is broken. Besides causing DSBs indirectly, high levels of ROS can also directly induce frank DSBs [178, 179]. PLP:mtPstI mice, in which DSBs can be timely and reversibly induced in mtDNA from oligodendrocytes, have been used to study the role of DSBs in oligodendropathy [180]. MtDNA encodes several key proteins for the ETC (complexes I, III, IV, V) [181]. MS-like features, including CNS inflammation, demyelination, and axonal injury, were observed in PLP:mtPstI mice following the induction of DSBs in oligodendroglial mtDNA. It was proposed that excessive ROS production amplified these outcomes by causing additional DNA damage and interfering with cell operations [180].

\section{Oxidative stress and DNA repair in OPCs}

During CNS ageing and disease, a complex network of repair pathways functions to detect and resolve DNA damage [182]. Some of the major pathways include excision repair (nucleotide excision repair [NER] and base excision repair [BER]) and recombinational (or double-strand break) repair (DSBR) [183]. Among the different glial cell types, the oligodendrocyte lineage appears to be the least capable of repairing DNA damage. In addition, DNA repair protein levels decrease in adult and aged OPCs compared to neonatal OPCs [34, 184]. NER resolves bulky DNA distortions, including adducts caused by oxidative damage such as cyclopurines. Following recognition, the NER pathways entail the excision of a 25-30 nucleotide segment, leaving behind an undamaged single-stranded DNA gap that a DNA polymerase uses as a template to correctly regenerate double-stranded DNA [185]. BER is involved in the removal and subsequent replacement of primarily non-distorting damaged bases and typically entails just a single-nucleotide re-synthesis event. Glycosylases initiate BER by excising a specific damaged DNA base (for example, 8-oxoguanine glycosylase (OGG1) recognizes 8-oxoG) from the DNA backbone, leaving behind an abasic (or AP) site repair intermediate. The subsequent steps of BER involve single-strand cleavage at the AP site, termini clean-up, repair synthesis and nick ligation to complete the process [186]. Both the nuclear and mitochondrial compartments house DNA repair mechanisms to maintain genome stability, with BER being the primary system in the latter.
Whereas astrocytes were able to fully repair mtDNA damage following a $6 \mathrm{~h}$ exposure to menadione, which mimics ETC-induced ROS, oligodendrocytes showed incomplete repair over the same time frame, with decent repair observed during the first $2 \mathrm{~h}$ (about 50\%) yet minimal repair in the following $4 \mathrm{~h}$ (an additional 15\%) [184]. The same study showed that menadione exposure leads to more mtDNA breaks in oligodendrocytes than astrocytes, supportive of either increased damage susceptibility or reduced repair capacity. When the concentration of menadione was doubled, more mtDNA breaks occurred in astrocytes as well but they were still able to reach full repair [184]. DNA repair in oligodendrocytes was enhanced by increasing OGG1 activity via transfection of a mitochondrial transport sequence upstream of the OGG1 gene [187], consistent with an overall lower BER capacity.

Recombinational repair (DSBR) has evolved to cope with various forms of DNA DSBs. DSBR mechanisms involve two primary pathways: nonhomologous end joining (NHEJ) and homologous recombination (HR). For the latter, a sister chromatid needs to be available (G2/S phase) to function as a template to permit faithful DSB resolution via the exchange of homologous genetic information. HR, which is tightly integrated with DNA replication to cope with one-ended DSBs that arise during replicative stress, is not vastly utilised in aged OPCs since they are mainly in G0/G1 phase [188]. NHEJ does not require a homologous template and directly anneals the two DNA ends that were formed at a frank (two-ended) DSB. Although NHEJ is the main mechanism in OPCs, it is error-prone as it typically involves the processing of the original sequence by a nuclease or polymerase to facilitate ligation [183, 185, 189, 190]. In many cases, the ability to detect DSBs relies on the MRN complex (composed of MRE11, RAD50 and NBS1). In the oligodendrocyte lineage, CNS-specific inactivation of the $\mathrm{Nbn}$ gene, which encodes NBS1, leads to hypomyelination via oligodendrocyte apoptosis and a lack of OPC differentiation by dysregulation of transcription regulators (HDACs, MYRF, etc.) [191, 192]. This study illustrates the necessity of DSBR in OPCs.

Based on the limited studies performed thus far, it appears that OPC differentiation can be impeded due to the lack of efficient DNA repair. In addition, future research should explore whether enzymes needed for DNA repair in OPCs are also involved in the cell differentiation program, as these competing interests may hinder differentiation when DNA damage is abundant $[172,193]$.

\section{Interference of ROS with epigenetics in OPCs}

ROS are known as modulators of the epigenetic machinery. The next sections discuss histone modifications, DNA 
methylation and miRNAs in the context of ROS and the effect on OPC function and differentiation.

\section{Histone modifications, ROS and OPCs}

The strongest link between ROS and OPC differentiation, in terms of the epigenetic machinery, has been established for histone modifications. A vast array of changes to histone tails occur, with (de)acetylation of lysine residues being the most prevalent modification [194]. Histone acetyltransferases (HATs) introduce the acetylation, which weakens the interaction of histone proteins with DNA, resulting in a more open chromatin structure. Histone deacetylases (HDACs) exert the opposite effect by removing the acetyl group leading to chromatin compaction and less accessibility for transcription factors. By controlling DNA availability, the interplay between HATs and HDACs influences gene expression profiles [195]. ROS can tip this balance by reducing histone deacetylation, although specific increases in HDAC activity have also been observed [196]. $\mathrm{H}_{2} \mathrm{O}_{2}$ exposure leads to a reduction in overall HDAC levels, as well as HDAC2 inactivation [197]. It is thought that enhanced HDAC activity is dependent on phosphorylation, which can be blocked by ROS such as peroxynitrite [197]. Additionally, RCS (e.g. $\mathrm{HNE}$ ) are able to cause alkylation of HDACs, inhibiting its function and altering chromatin dynamics [198].

HDAC activity is known to be required for OPC differentiation. Several in vitro and in vivo experiments using (unspecific) HDAC inhibitors have shown a decrease in differentiation, probably linked to failed suppression of inhibitory factors, including ID2, SOX2 and ID4 [54, 199-202]. OPCs exposed to oxidative stress in vitro displayed reduced HDAC expression and activity, resulting in an increased global level of acetylated histone 3 and 4 compared to control [152]. Simultaneous deletion of HDAC1 and 2, which normally repress the Wnt pathway and switch TCF4 to an activator of OPC differentiation, led to severe OPC differentiation impairment [199]. Low HDAC activity in ageing brain also leads to higher expression of differentiation inhibitors SOX2, ID4 and HES5, as well as a downregulation of activator OLIG2 [54]. Using the cuprizone mouse model, it was shown that mimicking brain ageing by pharmacological HDAC inhibition causes defective remyelination [202].

HDACs are also involved in DNA repair. In particular, HDAC 1 and 2 can be recruited to DNA lesion sites to deacetylate Lys56 of $\mathrm{H} 3$ to facilitate chromatin remodeling. This process is involved in the promotion of NHEJ to repair DSBs. This observation suggests a dual role for HDAC in OPCs, with differentiation and DNA repair competing for its involvement [172]. Altogether, ROS disturb histone (de) acetylation dynamics in OPCs, which is directly linked to the observed differentiation block.

\section{DNA methylation, ROS and OPCs}

DNA methylation is mainly restricted to the addition of a methyl group $\left(-\mathrm{CH}_{3}\right)$ to the five positions on a cytosine $(5 \mathrm{mC})$ base followed by guanine (commonly referred to as a CpG site, of which $60-80 \%$ is methylated) $[54,203]$. Nearly $10 \%$ of $\mathrm{CpG}$ sites are found in $\mathrm{CpG}$ islands, regions with more than 50\% C/G content [54, 204]. Methylation of $\mathrm{CpG}$ sites induces gene silencing by blocking the binding of transcription factors and allowing binding of repressor molecules, such as MeCP2 [205]. DNA methylation patterns are controlled by the DNA methyltransferase enzymes DNMT1 (maintenance) and DNMT3a/b (de novo methylation) [206]. DNA demethylation is initiated by hydroxylation of $5 \mathrm{mC}$ to $5 \mathrm{hmC}$ by ten-eleven translocation (TET) enzymes [54].

During oxidative stress, the formation of the oxidative base lesion 8-oxoG in $\mathrm{CpG}$ islands inhibits the binding of any methylation-controlling proteins (DNMT, TET) and disrupts gene expression. In addition, the hydroxylation of $5 \mathrm{mC}$ by ROS interferes with epigenetic signaling, since it may mimic demethylation (5hmC) [207]. ROS are also able to increase TET activity and therefore induce additional demethylation and overall hypomethylation [208]. Conversely, ROS can indirectly reduce DNMT activity by reducing the availability of the essential cofactor SAM [208]. However, ROS can also act as a catalyst for DNMTs and promote specific hypermethylation. For instance, $\mathrm{O}_{2}{ }^{-}$is capable of deprotonation of $\mathrm{C} 5$ on cytosine, increasing base reactivity and allowing more efficient methyl transfer [209]. Moreover, when DSBs occur, $\mathrm{H}_{2} \mathrm{O}_{2}$ exposure can lead to the recruitment of a gene silencing complex that includes DNMT1, resulting in hypermethylation of $\mathrm{CpG}$ sites in specific regions of the genome [208].

DNA methylation patterns change during ageing and disease, and can also be observed in response to various exogenous stimuli. While a global reduction of methylation (hypomethylation) is observed in ageing [210], selective hypermethylation has been reported in ageing and neurodegenerative disorders as well. In OPCs, DNA methylation is involved in regulating the proliferative state, but also in controlling alternative splicing and protein synthesis necessary for myelin formation [206]. DNA methylation plays a crucial role in the transition from OPC to oligodendrocyte by regulating its cell cycle exit. The observation that hypomethylation occurs with age also holds true for OPCs. A recent study measuring DNA methylation in OPCs revealed a significant drop in DNA methylation in aged rats, which was consistent with a decrease in DNMT1 expression and activity [211]. The role of DNMT1 in OPC differentiation is further highlighted by the fact that genetic ablation of DNMT1 results in hypomyelination and defective OPC differentiation [212]. Ablation of DNMT3a led to a differentiation block in OPCs and insufficient remyelination after 
lysolecithin-induced demyelination [213]. Furthermore, OPC differentiation seems to be characterised by a progressive loss of $5 \mathrm{hmC}$ signaling, which has received more attention in recent years as being more than just an intermediate during demethylation. ROS are capable of interfering with this pathway by hydroxylation [207, 214]. These observations provide a rationale to further study OPC differentiation in the context of ROS affecting DNA methylation.

\section{MicroRNAs, ROS and OPCs}

MiRNAs are small non-coding RNAs that make up a family of endogenous gene expression regulators by influencing mRNA translation [54]. This modulatory effect is most often accomplished by means of base-pair complementarity between the miRNA and the 3'-UTR region of the messenger RNA (mRNA) target $[215,216]$. The RNA-specific endonuclease Dicer is crucial for the cleavage of pre-miRNA and the formation of the active miRNA species, which can bind to mRNA and accomplish gene silencing [215].

Abnormalities in miRNA biogenesis and function are observed in neurodegenerative disorders (e.g. AD, ALS and PD), and stimulating miRNA biogenesis elicits protective effects in animal models for ALS and PD [217]. Additionally, oxidative stress and the miRNA system appear closely entwined. For example, oxidative stress deregulates both miRNA biogenesis and activity, leading to cellular stress and consequently ROS production. Oxidative stress induction (in silico, in vitro and in vivo) is known to cause a variety of changes to the miRNA system, including both down- and upregulation of specific miRNAs. ROS also affect miRNAs that target oxidative stress-modulating genes and transcription factors [218]. ROS can even induce these changes in miRNA expression through its effect on epigenetic modifications such as the aforementioned ROS-mediated change in DNA methylation and histone modification patterns. Finally, $\mathrm{H}_{2} \mathrm{O}_{2}$ treatment has been shown to decrease the expression of Dicer, which in turn results in decreased miRNA maturation [219].

Several miRNAs have been identified to play a crucial role in OPC differentiation [54]. A microRNAome study indicated three highly induced (10-100x) miRNAs: miR219 , miR-138 and miR-338. The most abundant of the three, miR-219, directly represses the expression of, among others, SOX6 and PDGF $\alpha$ R, which normally inhibit OPC differentiation by promoting proliferation [220]. Therefore, miR-219 is crucial in allowing OPCs to exit the proliferation stage and initiate differentiation. However, in MS, a downregulation of miR-219, as well as miR-338, has been observed in chronic inactive lesions [221]. MiR-27a is also important for cell cycle regulation [222]. A steady-state level of this miRNA appears to be necessary for proper oligodendrocyte development; however, increased levels are associated with impaired OPC differentiation. Interestingly, the negative effect of miR-27a on OPC differentiation was not rescued by co-transfection of miR-219 as assessed by MBP expression. This study indicates that inhibitory cues are powerful and can suppress positive cues [223]. MiR-27a is linked to oxidative stress pathways, since its expression is increased by ROS and miR-27a specifically affects ROS regulating pathways (MAPK, apoptosis, cell survival, etc.) [218, 219]. Furthermore, deletion of Dicer impaired OPC differentiation illustrating that OPCs lacking mature miRNAs undergo some sort of a differentiation block [220].

Collectively, the current evidence indicates that oxidative stress can affect histone modifications, DNA methylation patterns, and miRNA profiles. In doing so, it can interfere with OPC differentiation and contribute to ageing and neurodegenerative disease. The exact mechanisms and links between epigenetic mechanisms and OPC differentiation remain to be elucidated and pose an interesting research field to explore.

\section{Mitochondrial oxidative damage in OPCs}

Insufficient metabolic/mitochondrial adaptations during OPC differentiation can result from the aforementioned (epi)genetic differentiation block. Yet, oxidative stress may also directly impair metabolic processes to ultimately hinder OPC differentiation and (re)myelination.

Mitochondria are redox-sensitive organelles with an essential role in numerous cellular homeostatic processes, while also affecting cell differentiation. Moderate ROS fluctuations are involved in physiological responses, but chronic and/or exaggerated elevations in ROS interfere with mitochondrial function and initiate a vicious cycle of (mitochondrial) ROS production and ROS-inflicted (mitochondrial) damage [224, 225]. Oxidative and carbonyl stress can cause and perpetuate modifications to mitochondrial membrane phospholipids, enzymes and ETC complexes, as well as mtDNA, as discussed above [226-229]. ETC complex I, in particular, is a frequently described target of oxidative modifications implicated in ageing, ischemia-reperfusion, PD and other CNS disorders [230, 231]. Interestingly, when complex I was inhibited in OPCs by a low dose of rotenone that does not compromise cell viability or ATP synthesis, OPC differentiation was blocked in vitro [33, 61]. Differentiating oligodendrocytes were more sensitive to complex I inhibition compared to undifferentiated or already differentiated oligodendrocytes. Complex IV inhibition by sublethal doses of sodium azide briefly prior to or throughout OPC differentiation substantially impaired the formation of complex oligodendrocyte processes [64]. The adverse effect of sodium azide on the mitochondria was intensified in Nrf2-knockdown cells and partly counteracted in Nrf2-hyperactivated (via Keap1 knockdown) cells, implying the importance of 
antioxidant defence [232]. In addition, homozygous deletion of succinate dehydrogenase subunit $\mathrm{D}$, an important component of both the citric acid cycle and ETC complex II, hindered neuronal and oligodendrocyte (but not astrocyte) differentiation causing brain atrophy [233]. Finally, mice that display abnormalities in ETC oxidative phosphorylation proteins due to eIF2B mutation display defective OPC differentiation with suppressed neurite length in vitro [234].

These lines of evidence clearly suggest an important role for the mitochondrial machinery in OPC differentiation, process formation and myelination. Notably, despite the lack of evidence causally linking ROS/RCS to defects in mitochondrial function and OPC differentiation, it is plausible to hypothesise that oxidative damage to mitochondria elicits such effects.

\section{Oxidative stress, metabolic signalling and OPC differentiation/myelination}

Inhibiting mitochondrial function in OPCs impairs cell growth, differentiation and myelination, and vice versa. Normal mitochondrial biogenesis is controlled by peroxisome proliferator-activated receptor gamma coactivator 1-alpha (PGC-1 $\alpha$ ), a transcriptional coactivator that interacts with and activates a variety of nuclear transcription factors (e.g. TFAM, PPARs, NRFs, RXRs) [235]. Hereby, PGC- $1 \alpha$ also promotes antioxidant defences and cellular lipid metabolism. The regulation and role of PGC- $1 \alpha$ in the oligodendrocyte lineage requires further research; however, Jensen et al. suggested that the activation and nuclear translocation of PGC- $1 \alpha$ coincide with oligodendrocyte differentiation and is downregulated afterwards [236]. Knockout studies in mice have implicated PGC-1 $\alpha$ in myelinogenic programs including oligodendrocyte lipid/cholesterol synthesis and MBP/ PLP transcription [236-238]. A deficiency in PGC-1 $\alpha$ led to an increase in VLCFAs and a disruption of cholesterol homeostasis in the CNS presumably due to peroxisomal malfunction, whereas enhanced PGC- $1 \alpha$ activation accelerated myelin thickening following white matter demyelination in mice [236]. The mitochondrial transcription factor A (TFAM) is a PGC- $1 \alpha$-controlled nuclear-encoded mitochondrial protein that is essential for the maintenance, transcription and replication of mtDNA. Deletion of Tfam in Schwann cells caused mitochondrial ETC deficiency, characterised by the preservation of energy levels but a shift in lipid metabolism from fatty acid synthesis toward oxidation. As a result, Viader et al. observed downregulation of lipid synthesis enzymes (e.g. Srebp1, Fasn, Acc2), depletion of myelin lipid components, chronic demyelination, disturbed glia-axon interaction and axonal degeneration [239, 240]. In addition, peroxisome proliferator-activated receptors (PPARs) have pleiotropic beneficial effects. The $\alpha, \beta$ and $\gamma$ isoforms have been shown to boost OPC differentiation under normal conditions and/or preserve OPC differentiation under conditions of oxidative stress or inflammation [85, 241-246]. PPAR effects have been ascribed to their binding to peroxisome proliferator response elements (PPREs) present in the promoter regions of target genes. These include genes involved in lipid/cholesterol metabolism, mitochondria and antioxidant defence, but also in cell plasticity and differentiation programs such as CREB [247, 248].

Interestingly, ROS are well-known activators of PGC- $1 \alpha$ signalling. Although underlying signalling pathways in OPCs remain speculative, AMP-activated protein kinase (AMPK) and mitogen-activated protein kinase (MAPK) are potent activators of PGC- $1 \alpha$ in response to changes in the cellular redox state and energy levels [249, 250]. The AMPK stimulator metformin has been used to restore the differentiation capacity of aged OPCs, improve remyelination efficiency [33] and protect against demyelination [251]. Although such effects may also be mediated by surrounding CNS cells, Neumann et al. showed that (at least part of) the effect is cell-intrinsic to OPCs and may involve improved mitochondrial function [33]. Likewise, the ROS-induced p38 and ERK MAPK pathways are required to regulate the timing of oligodendrocyte differentiation [252-254] and myelin preservation [255]. Genetic loss-of-function studies strongly suggest a role for ERK1/2 signalling as a positive regulator of myelination both in the central and peripheral nervous system, whilst a gain-of-function in MAPK results in hypermyelination albeit independent of glial cell differentiation $[33,256]$.

The downstream effects of AMPK and MAPK activation are widespread, but enhancement of mitochondrial biogenesis, antioxidant defence and cellular energy metabolism may explain (part of) the differentiation-enhancing effects of physiological elevations in ROS. However, ageing and various pathologies are characterised by increased oxidative stress, which disturbs, not enhances, mitochondrial biogenesis. Neumann et al. found that aged OPCs from rats exhibit reduced (re)myelination capacity along with elevated p38 MAPK signalling [33]. In addition, $\mathrm{H}_{2} \mathrm{O}_{2}$-induced oligodendrocyte cytotoxicity was accompanied by MAPK activation but prevented by MAPK inhibition [257]. Also, it was hypothesised that the destructive effects of inflammation and oxidative stress on OPCs are mediated by AMPK [258]. The conflicting data on oxidative stress-related pathways draw a more complicated picture and underscore the need for future research to understand how oxidative/carbonyl stress affect different metabolic signals in OPCs. We currently do not know which signals are desired for optimal OPC differentiation, antioxidant defence and myelination. As was suggested for stem cell differentiation [259], the effect of ROS on OPC function is likely dependent on dose, source, and context.

ROS and RCS can disturb metabolic signalling in multiple ways. First, oxidative modifications to important proteins 
may directly impair signalling responses. However, OPCspecific evidence is currently missing. Proteins involved in antioxidant and mitochondrial signalling that are known to be expressed in OPCs but are vulnerable to oxidative modification include, amongst others, LDL receptor-related protein-1 (LRP1) [260, 261], AMPK [262, 263], and PGC-1 $\alpha$ [237, 264]. Second, (over)activation of oxidative stress pathways over long periods may be harmful instead of helpful [250]. This idea was proposed for AMPK activation, which - despite its beneficial effects on mitochondrial adaptations - promotes catabolic over anabolic processes; for example by inhibiting ACC1/2, HMGCR [239, 265, 266], SREBP1/2 [267, 268], and mTORC1 [269, 270]. The aforementioned pathways were found to be involved in the development, growth and myelination capacity of oligodendrocytes. Such observations have led some researchers to suggest that upregulating mTOR in OPCs via AMPK downregulation (instead of AMPK upregulation, e.g. via metformin) may be a therapeutic strategy to boost myelination in neurodegenerative/psychiatric disorders such as schizophrenia [36]. Finally, it also appears that oligodendrocyte Nrf2 and PGC- $1 \alpha$ expression is reduced compared to other CNS cell types in MS, suggesting an impaired oxidative stress response [158, 271]. Consequently, oligodendrocytes (and potentially OPCs and developing oligodendrocytes) may lack the physiological adaptations needed to prevent mitochondrial failure, resulting in the inability to protect themselves against oxidative injury.

\section{Various other effects of oxidative stress}

Oxidative and carbonyl stress have been linked to changes in protein (mis)folding, autophagy, endoplasmic reticulum (ER) stress and cellular $\mathrm{Ca}^{2+}$ handling. Interestingly, aged OPCs seem more vulnerable to the deleterious consequences of aggregation-prone proteins. Whilst this has mainly been described in neurons from AD, PD and Huntington patients, it also seems to occur in oligodendrocytes [34]. Both the induction and the clearance of protein aggregates may be triggered by oxidative stress. An in-depth review of the aforementioned mechanisms in OPCs is out of the scope of this manuscript.

\section{Interaction between transcriptional and metabolic events}

Above, we discussed separately the effect of oxidative/ carbonyl stress on the transcriptional and metabolic regulation of OPC differentiation. However, transcriptional and metabolic events are often tightly interconnected and can reciprocally influence one another. For example, mitochondrial metabolites such as ATP, acetyl-CoA, NAD ${ }^{+}$, $\alpha$-ketoglutarate and ROS influence (epi)genetic events at the nuclear level (e.g. DNA repair, histone modifications, transcription factors) [272]. Thus, future research investigating ROS/RCS and OPC dysfunction in neurodegeneration should not only keep in mind the involvement of each component but also their interaction.

\section{Therapeutic approaches to tackle oxidative stress-induced OPC dysfunction in neurodegeneration}

It is clear that protecting OPCs under conditions of elevated oxidative/carbonyl stress may hold great therapeutic value in neurodegenerative disorders. To develop fully tailored therapies, a better understanding of the different underlying mechanisms that were covered in this review is warranted. Nevertheless, several interesting therapeutic approaches to tackle oxidative stress-related OPC dysfunction are emerging. Although recently several remyelination-inducing drugs (e.g. anti-LINGO-1, clemastine fumarate) have come to attention, it should be emphasised that so far none of these treatments have reached FDA/EMA approval for induction of remyelination in demyelinating disorders.

By aiming to not only promote OPC survival but also to maintain normal OPC function and (re)myelination, therapies could target either the cause and/or consequences of oxidative and carbonyl stress. Immune-modulatory and anti-inflammatory treatments may protect CNS cells, including OPCs, from excessive oxidative stress [28, $273,274]$. In addition, a variety of specific antioxidant approaches exist. One common goal is to increase cellular $\mathrm{GSH}$, e.g. by administering $\mathrm{N}$-acetylcysteine (NAC) as a source of cysteine (the rate-limiting substrate for GSH synthesis) or by protecting against GSH depletion via increasing alternative antioxidant or carbonyl quenching pathways (e.g. carnosine, aminoguanidine, flavenoids) [275]. NAC has shown beneficial effects in the context of PD, AD, stroke, MDD, schizophrenia, obsessive-compulsive disorder and neuropathic pain [276-278]. Protective effects of NAC have also been demonstrated for oligodendrocytes and OPCs [86, 279-281]. Alternatively, cellular GSH levels, and thereby antioxidant capacity, may be increased by modulating membrane transporters such as the excitatory amino acid transporter 3 (EAAT3). EAAT3 facilitates cysteine transport and is highly expressed in OPCs [282]. Mice overexpressing neuronal EAAT3 contain increased GSH in the cortex, striatum and hippocampus [283]. Whether OPC-specific EAAT3-mediated cysteine transport protects OPCs during oxidative stress is currently under investigation. Stimulating enzymatic antioxidants via the Nrf2/ARE pathway is another promising approach, as recently demonstrated by Lim et al., who reported that Protandim (Nrf2 activator) rescued OPCs from oxidative 
stress-induced differentiation arrest [126]. Likewise, dimethyl fumarate, another Nrf2 activator, directly impacts oligodendrocytic citric acid cycle intermediates, GSH and lipids, factors that are associated with protection from oxidative stress [284, 285]. Despite the numerous possibilities, many therapeutic options have not yet been explored in OPCs. For example, PGC- $1 \alpha$ signalling is an exciting candidate due to its widespread effects on cell metabolism and antioxidant functions. In astrocytes, upregulation of PGC- $1 \alpha$ resulted in reduced ROS production and increased resistance to oxidative attack [286]. Several studies have also shown the benefits of PPAR agonists on OPC and oligodendrocyte function under both normal and diseased conditions [85, 241-246]. Activating AMPK signalling via metformin is able to rejuvenate aged OPCs, restoring their differentiation capacity both in vitro and in vivo [33]. Finally, Biotin can counter (mitochondrial) oxidative stress, enhance antioxidant function and improve metabolic function (e.g. fatty acid ad cholesterol synthesis) in oligodendrocytes [287], potentially also serving to support OPCs [288]. However, a recent trial reported no efficacy in progressive MS (NCT02936037). As discussed above, the major signalling response in OPCs in different pathological conditions is a topic of hot debate.

Alternatively, several genetic and epigenetic interventions aiming to protect OPCs or boost DNA repair are currently under investigation. These include, for example, DNA damage response (DDR) activators, DNA-binding proteins with epigenetic modifiers, or modulators of HDACs and DNMTs [54, 289]. A variety of non-specific inhibitors against epigenetic enzymes (e.g. TSA for HDAC inhibition, 5-aza for hypomethylation) exist, although they are mostly known in the context of cancer treatment due to their pro-apoptotic effects [290]. When applied to oligodendrocytes, however, these drugs have no beneficial effects, in addition to being non-selective and cytotoxic at high doses [54]. Thus, more selective activation or inhibition of specific enzymes is required. Notably, a recent paper found that activation of HDAC1, which in turn stimulates OGG1 repair activity, offers a therapeutic strategy for the treatment of age- or AD-related cognitive decline and neurodegeneration [291]. In OPCs, specifically, OGG1 enhancement in mitochondria increases mtDNA repair and cell survival after oxidative insults [187, 292]. Other potential approaches to boost DNA repair include the antibacterial agent enoxacin, which is known to enhance Dicer activity. Increased Dicer activity enhances the formation of miRNAs important for the DDR, improving the recruitment of DDR proteins to damaged sites. In HeLa cells, this phenomenon allows more accurate NHEJ and cell survival [289]; however, such approaches remain largely unexplored in the field of OPC research.

\section{Conclusion}

OPC dysfunction is increasingly being linked to many neurodegenerative disorders that are characterised by elevated oxidative and carbonyl stress. Yet, future research with a specific focus on the source and severity of oxidative/carbonyl stress in OPCs under different pathological conditions is warranted. In this review, we have proposed several (epi)genetic and metabolic alterations that could underlie the oxidative stress-induced OPC dysfunction (differentiation block) in neurodegeneration. Deciphering the precise mechanisms of OPC dysfunction during oxidative/carbonyl stress will pave the way for targeted therapeutics with applications in a variety of neurodegenerative disorders.

Authors' contributions JS, LvV and TV conceptualised the review article; JS and LvV performed the literature search; JS, LvV, MS, AT, TV drafted the manuscript; JS, LvV, MS, AT, JvH, DMW, PM, EP, $\mathrm{NH}, \mathrm{BOE}, \mathrm{WD}, \mathrm{RS}$ and TV critically revised the work and agreed with publication.

Funding The lead authors were supported by funding from Fonds Wetenschappelijk Onderzoek (FWO) Vlaanderen.

Availability of data and material Not applicable.

Code availability Not applicable.

\section{Declarations}

Conflict of interest The authors declare that they have no conflict of interest.

Ethical approval Not applicable.

Informed consent Not applicable.

Open Access This article is licensed under a Creative Commons Attribution 4.0 International License, which permits use, sharing, adaptation, distribution and reproduction in any medium or format, as long as you give appropriate credit to the original author(s) and the source, provide a link to the Creative Commons licence, and indicate if changes were made. The images or other third party material in this article are included in the article's Creative Commons licence, unless indicated otherwise in a credit line to the material. If material is not included in the article's Creative Commons licence and your intended use is not permitted by statutory regulation or exceeds the permitted use, you will need to obtain permission directly from the copyright holder. To view a copy of this licence, visit http://creativecommons.org/licenses/by/4.0/. 


\section{References}

1. Rowitch DH, Kriegstein AR (2010) Developmental genetics of vertebrate glial-cell specification. Nature 468:214-222. https:// doi.org/10.1038/nature09611

2. Emery B (2010) Regulation of oligodendrocyte differentiation and myelination. Science 330:779-782. https://doi.org/10.1126/ science. 1190927

3. Bradl M, Lassmann H (2010) Oligodendrocytes: biology and pathology. Acta Neuropathol 119:37-53. https://doi.org/10.1007/ s00401-009-0601-5

4. Elbaz B, Popko B (2019) Molecular control of oligodendrocyte development. Trends Neurosci 42:263-277. https://doi. org/10.1016/j.tins.2019.01.002

5. Fernandez-Castaneda A, Gaultier A (2016) Adult oligodendrocyte progenitor cells-multifaceted regulators of the CNS in health and disease. Brain Behav Immun 57:1-7. https://doi. org/10.1016/j.physbeh.2017.03.040

6. Kuhn S, Gritti L, Crooks D, Dombrowski Y (2019) Oligodendrocytes in development, myelin generation and beyond. Cells 8:1424

7. Hill RA, Li AM, Grutzendler J (2018) Lifelong cortical myelin plasticity and age-related degeneration in the live mammalian brain. Nat Neurosci 21:683-695. https://doi.org/10.1038/s4159 3-018-0120-6

8. Pan S, Mayoral SR, Choi HS et al (2020) Preservation of a remote fear memory requires new myelin formation. Nat Neurosci 23:487-499. https://doi.org/10.1038/s41593-019-0582-1

9. Young KM, Psachoulia K, Tripathi RB et al (2013) Oligodendrocyte dynamics in the healthy adult CNS: evidence for myelin remodeling. Neuron 77:873-885. https://doi.org/10.1016/j. neuron.2013.01.006

10. Fields RD, Bukalo O (2020) Myelin makes memories. Nat Neurosci 23:469-470. https://doi.org/10.1038/s41593-020-0606-x

11. McKenzie IA, Ohayon D, Li H et al (2014) Motor skill learning requires active central myelination. Science (80-) 346:318322. https://doi.org/10.1126/science. 1254960

12. Steadman PE, Xia F, Ahmed M et al (2020) Disruption of oligodendrogenesis impairs memory consolidation in adult mice. Neuron 105:150-164.e6. https://doi.org/10.1016/j.neuro n.2019.10.013

13. Wang F, Ren S, Chen J et al (2020) Myelin degeneration and diminished myelin renewal contribute to age-related deficits in memory. Nat Neurosci 23:481-486. https://doi.org/10.1038/ s41593-020-0588-8.Myelin

14. de Faria O, Gonsalvez DG, Nicholson M, Xiao J (2019) Activity-dependent central nervous system myelination throughout life. J Neurochem 148:447-461. https://doi.org/10.1111/ jnc. 14592

15. Tomassy GS, Dershowitz LB, Arlotta P (2016) Diversity matters: a revised guide to myelination. Trends Cell Biol 26:135-147. https://doi.org/10.1016/j.tcb.2015.09.002

16. Franklin RJM, Ffrench-Constant C (2017) Regenerating CNS myelin-from mechanisms to experimental medicines. Nat Rev Neurosci 18:753-769. https://doi.org/10.1038/nrn.2017.136

17. Moyon S, Dubessy AL, Aigrot MS et al (2015) Demyelination causes adult CNS progenitors to revert to an immature state and express immune cues that support their migration. J Neurosci 35:4-20. https://doi.org/10.1523/JNEUROSCI.0849-14.2015

18. Plemel JR, Liu W, Yong VW (2017) Remyelination therapies: multiple sclerosis. Nat Rev Drug Discov 16:617-634. https://doi. org/10.1038/nrdnrd.2017.115

19. Mauney SA, Pietersen CY, Sonntag KC, Woo TUW (2015) Differentiation of oligodendrocyte precursors is impaired in the prefrontal cortex in schizophrenia. Schizophr Res 169:374-380. https://doi.org/10.1016/j.schres.2015.10.042

20. Dendrou CA, Fugger L, Friese MA (2015) Immunopathology of multiple sclerosis. Nat Rev Immunol 15:545-558

21. Tognatta R, Miller RH (2016) Contribution of the oligodendrocyte lineage to CNS repair and neurodegenerative pathologies. Neuropharmacology 110:539-547. https://doi.org/10.1016/j. neuropharm.2016.04.026

22. Liu Y, Zhou J (2013) Oligodendrocytes in neurodegenerative diseases. Front Biol (Beijing) 8:127-133. https://doi.org/10.1007/ s11515-013-1260-4

23. Takagi S, Hayakawa N, Kimoto H et al (2007) Damage to oligodendrocytes in the striatum after MPTP neurotoxicity in mice. J Neural Transm 114:1553-1557. https://doi.org/10.1007/s0070 2-007-0790-9

24. Bryois J, Skene NG, Hansen TF et al (2020) Genetic identification of cell types underlying brain complex traits yields insights into the etiology of Parkinson's disease. Nat Genet 52:482-493. https://doi.org/10.1038/s41588-020-0610-9

25. Hamidi M, Drevets WC, Price JL (2004) Glial reduction in amygdala in major depressive disorder is due to oligodendrocytes. Biol Psychiatry 55:563-569. https://doi.org/10.1016/j.biops ych.2003.11.006

26. Tse KH, Cheng A, Ma F, Herrup K (2018) DNA damageassociated oligodendrocyte degeneration precedes amyloid pathology and contributes to Alzheimer's disease and dementia. Alzheimer's Dement 14:664-679. https://doi.org/10.1016/j. jalz.2017.11.010

27. Neely SA, Williamson JM, Klingseisen A et al (2020) New oligodendrocytes exhibit more abundant and accurate myelin regeneration than those that survive demyelination. bioRxiv. https:// doi.org/10.1101/2020.05.22.110551

28. Rodgers JM, Robinson AP, Miller SD (2013) Strategies for protecting oligodendrocytes and enhancing remyelination in multiple sclerosis. Discov Med 16:53-63

29. Franklin RJM (2002) Why does remyelination fail in multiple sclerosis? Nat Rev Neurosci 3:705-714. https://doi.org/10.1038/ nrn917

30. Yeung MSY, Djelloul M, Steiner E et al (2019) Dynamics of oligodendrocyte generation in multiple sclerosis. Nature 566:538542. https://doi.org/10.1038/s41586-018-0842-3

31. Ahmed Z, Asi YT, Lees AJ et al (2013) Identification and quantification of oligodendrocyte precursor cells in multiple system atrophy, progressive supranuclear palsy and Parkinson's disease. Brain Pathol 23:263-273. https://doi.org/10.111 1/j.1750-3639.2012.00637.x

32. Neumann B, Segel M, Chalut KJ, Franklin RJM (2019) Remyelination and ageing: reversing the ravages of time. Mult Scler J 25:1835-1841. https://doi.org/10.1177/1352458519884006

33. Neumann B, Baror R, Zhao C et al (2019) Metformin restores CNS remyelination capacity by rejuvenating aged stem cells. Cell Stem Cell 25:473-485.e8. https://doi.org/10.1016/j. stem.2019.08.015

34. de la Fuente AG, Queiroz RML, Ghosh T et al (2020) Changes in the oligodendrocyte progenitor cell proteome with ageing. Mol Cell Proteomics. https://doi.org/10.1074/mcp.RA120.002102

35. Ruckh JM, Zhao J-W, Shadrach JL et al (2012) Rejuvenation of regeneration in the aging central nervous system. Cell Stem Cell 10:96-103. https://doi.org/10.1038/jid.2014.371

36. Maas DA, Vallès A, Martens GJM (2017) Oxidative stress, prefrontal cortex hypomyelination and cognitive symptoms in schizophrenia. Transl Psychiatry 7:e1171. https://doi.org/10.1038/ tp. 2017.138

37. McKenzie AT, Moyon S, Wang M et al (2017) Multiscale network modeling of oligodendrocytes reveals molecular components of myelin dysregulation in Alzheimer's disease. 
Mol Neurodegener 12:1-20. https://doi.org/10.1186/s1302 4-017-0219-3

38. Pietrzak M, Papp A, Curtis A et al (2016) Gene expression profiling of brain samples from patients with Lewy body dementia. Biochem Biophys Res Commun 479:875-880. https://doi. org/10.1016/j.bbrc.2016.09.114

39. Kuhlmann T, Miron V, Cuo Q et al (2008) Differentiation block of oligodendroglial progenitor cells as a cause for remyelination failure in chronic multiple sclerosis. Brain 131:1749-1758. https ://doi.org/10.1093/brain/awn096

40. Kotter MR, Li WW, Zhao C, Franklin RJM (2006) Myelin impairs CNS remyelination by inhibiting oligodendrocyte precursor cell differentiation. J Neurosci 26:328-332. https://doi. org/10.1523/JNEUROSCI.2615-05.2006

41. Bonfanti E, Bonifacino T, Raffaele S et al (2020) Abnormal upregulation of GPR17 receptor contributes to oligodendrocyte dysfunction in SOD1 G93A mice. Int J Mol Sci 21:1-20. https ://doi.org/10.3390/ijms21072395

42. Goldman SA, Kuypers NJ (2015) How to make an oligodendrocyte. Development 142:3983-3995. https://doi.org/10.1242/ dev.126409

43. Turnescu T, Arter J, Reiprich S et al (2018) Sox 8 and Sox 10 jointly maintain myelin gene expression in oligodendrocytes. Glia 66:279-294. https://doi.org/10.1002/glia.23242

44. Zhu X, Zuo H, Maher BJ et al (2012) Olig2-dependent developmental fate switch of NG2 cells. Development 139:2299-2307. https://doi.org/10.1242/dev.078873

45. Cai J, Zhu Q, Zheng K et al (2010) Co-localization of Nkx6.2 and Nkx2.2 homeodomain proteins in differentiated myelinating oligodendrocytes. Glia 58:458-468. https://doi.org/10.1002/ glia.20937

46. Duncan GJ, Plemel JR, Assinck P et al (2017) Myelin regulatory factor drives remyelination in multiple sclerosis. Acta Neuropathol 134:403-422. https://doi.org/10.1007/s00401-017-1741-7

47. Li H, He Y, Richardson WD, Casaccia P (2009) Two-tier transcriptional control of oligodendrocyte differentiation. Curr Opin Neurobiol 19:479-485. https://doi.org/10.1016/j. conb.2009.08.004

48. Mitew S, Hay CM, Peckham H et al (2014) Mechanisms regulating the development of oligodendrocytes and central nervous system myelin. Neuroscience 276:29-47. https://doi.org/10.1016/j. neuroscience.2013.11.029

49. Stolt CC, Schlierf A, Lommes P et al (2006) SoxD proteins influence multiple stages of oligodendrocyte development and modulate SoxE protein function. Dev Cell 11:697-709. https:// doi.org/10.1016/j.devcel.2006.08.011

50. Liu Z, Hu X, Cai J et al (2007) Induction of oligodendrocyte differentiation by Olig2 and Sox 10: evidence for reciprocal interactions and dosage-dependent mechanisms. Dev Biol 302:683-693. https://doi.org/10.1016/j.ydbio.2006.10.007

51. Aprato J, Sock E, Weider M et al (2020) Myrf guides target gene selection of transcription factor Sox 10 during oligodendroglial development. Nucleic Acids Res 48:1254-1270. https://doi. org/10.1093/nar/gkz1158

52. Hornig J, Fröb F, Vogl MR et al (2013) The transcription factors Sox 10 and Myrf define an essential regulatory network module in differentiating oligodendrocytes. PLoS Genet 9:e1003907. https ://doi.org/10.1371/journal.pgen.1003907

53. Liu J, Casaccia P (2010) Epigenetic regulation of oligodendrocyte identity. Trends Neurosci 33:193-201. https://doi. org/10.1016/j.tins.2010.01.007

54. Tiane A, Schepers M, Rombaut B et al (2019) From OPC to oligodendrocyte: an epigenetic journey. Cells 8:1236. https://doi. org/10.3390/cells8101236

55. Miron VE, Kuhlmann T, Antel JP (2011) Cells of the oligodendroglial lineage, myelination, and remyelination.
Biochim Biophys Acta Mol Basis Dis 1812:184-193. https:// doi.org/10.1016/j.bbadis.2010.09.010

56. Baron W, Hoekstra D (2010) On the biogenesis of myelin membranes: sorting, trafficking and cell polarity. FEBS Lett 584:1760-1770. https://doi.org/10.1016/j.febslet.2009.10.085

57. Chong SYC, Rosenberg SS, Fancy SPJ et al (2012) Neurite outgrowth inhibitor Nogo-A establishes spatial segregation and extent of oligodendrocyte myelination. Proc Natl Acad Sci 109:1299-1304. https://doi.org/10.1073/pnas.1113540109

58. Poitelon Y, Kopec AM, Belin S (2020) Myelin fat facts: an overview of lipids and fatty acid metabolism. Cells 9:812. https://doi. org/10.3390/cells9040812

59. Hirrlinger J, Nave KA (2014) Adapting brain metabolism to myelination and long-range signal transduction. Glia 62:1749-1761. https://doi.org/10.1002/glia.22737

60. Saher G, Brügger B, Lappe-Siefke C et al (2005) High cholesterol level is essential for myelin membrane growth. Nat Neurosci 8:468-475. https://doi.org/10.1038/nn1426

61. Schoenfeld R, Wong A, Silva J et al (2010) Oligodendroglial differentiation induces mitochondrial genes and inhibition of mitochondrial function represses oligodendroglial differentiation. Mitochondrion 10:143-150. https://doi.org/10.1016/j. mito.2009.12.141

62. Schoor C, Brocke-Ahmadinejad N, Gieselmann V, Winter D (2019) Investigation of oligodendrocyte precursor cell differentiation by quantitative proteomics. Proteomics 19:1-11. https:// doi.org/10.1002/pmic.201900057

63. Rinholm JE, Vervaeke K, Tadross MR et al (2016) Movement and structure of mitochondria in oligodendrocytes and their myelin sheaths. Glia 64:810-825. https://doi.org/10.1002/glia.22965

64. Ziabreva I, Campbell G, Rist J et al (2010) Injury and differentiation following inhibition of mitochondrial respiratory chain complex IV in rat oligodendrocytes. Glia 58:1827-1837. https ://doi.org/10.1002/glia.21052

65. Marangon D, Boccazzi M, Lecca D, Fumagalli M (2020) Regulation of oligodendrocyte functions: targeting lipid metabolism and extracellular matrix for myelin repair. J Clin Med 9:470. https:// doi.org/10.3390/jcm9020470

66. Rinholm JE, Hamilton NB, Kessaris N et al (2011) Regulation of oligodendrocyte development and myelination by glucose and lactate. J Neurosci 31:538-548. https://doi.org/10.1523/JNEUR OSCI.3516-10.2011

67. Sánchez-Abarca LI, Tabernero A, Medina JM (2001) Oligodendrocytes use lactate as a source of energy and as a precursor of lipids. Glia 36:321-329. https://doi.org/10.1002/glia.1119

68. Kassmann CM (2014) Myelin peroxisomes-essential organelles for the maintenance of white matter in the nervous system. Biochimie 98:111-118. https://doi.org/10.1016/j.biochi.2013.09.020

69. Kassmann CM, Quintes S, Rietdorf J et al (2011) A role for myelin-associated peroxisomes in maintaining paranodal loops and axonal integrity. FEBS Lett 585:2205-2211. https://doi. org/10.1016/j.febslet.2011.05.032

70. Rone MB, Cui QL, Fang J et al (2016) Oligodendrogliopathy in multiple sclerosis: low glycolytic metabolic rate promotes oligodendrocyte survival. J Neurosci 36:4698-4707. https://doi. org/10.1523/JNEUROSCI.4077-15.2016

71. Simons M, Nave KA (2016) Oligodendrocytes: myelination and axonal support. Cold Spring Harb Perspect Biol 8:1-15. https:// doi.org/10.1101/cshperspect.a020479

72. Fünfschilling U, Supplie LM, Mahad D et al (2012) Glycolytic oligodendrocytes maintain myelin and long-term axonal integrity. Nature 485:517-521. https://doi.org/10.1038/nature11007

73. Ineichen BV, Zhu K, Carlström KE (2021) Axonal mitochondria adjust in size depending on g-ratio of surrounding myelin during homeostasis and advanced remyelination. J Neurosci Res 99:793-805. https://doi.org/10.1002/jnr.24767 
74. Dröse S, Brandt U (2012) Molecular mechanisms of superoxide production by the mitochondrial respiratory chain. In: Kadenbach B (ed) Mitochondrial oxidative phosphorylation. Springer, New York

75. Zhao RZ, Jiang S, Zhang L, Bin YuZ (2019) Mitochondrial electron transport chain, ROS generation and uncoupling (Review). Int J Mol Med 44:3-15. https://doi.org/10.3892/ijmm.2019.4188

76. Chance B, Sies H, Boveris A (1979) Hydroperoxide metabolism in mammalian organs. Physiol Rev 59:527-605. https://doi. org/10.1152/physrev.1979.59.3.527

77. Campbell GR, Ziabreva I, Reeve AK et al (2011) Mitochondrial DNA deletions and neurodegeneration in multiple sclerosis. Ann Neurol 69:481-492. https://doi.org/10.1002/ana.22109

78. Mahad D, Ziabreva I, Lassmann H, Turnbull D (2008) Mitochondrial defects in acute multiple sclerosis lesions. Brain 131:17221735. https://doi.org/10.1093/brain/awn105

79. Yao SY, Natarajan C, Sriram S (2012) NNOS mediated mitochondrial injury in LPS stimulated oligodendrocytes. Mitochondrion 12:336-344. https://doi.org/10.1016/j.mito.2012.01.002

80. Yao SY, Ljunggren-Rose A, Chandramohan N et al (2010) In vitro and in vivo induction and activation of nNOS by LPS in oligodendrocytes. J Neuroimmunol 229:146-156. https://doi. org/10.1016/j.jneuroim.2010.07.023

81. Boullerne AI, Benjamins JA (2006) Nitric oxide synthase expression and nitric oxide toxicity in oligodendrocytes. Antioxid Redox Signal 8:967-980. https://doi.org/10.1089/ars.2006.8.967

82. Johnstone JT, Morton PD, Jayakumar AR et al (2013) Inhibition of NADPH oxidase activation in oligodendrocytes reduces cytotoxicity following trauma. PLoS ONE 8:1-14. https://doi. org/10.1371/journal.pone.0080975

83. Accetta R, Damiano S, Morano A et al (2016) Reactive oxygen species derived from NOX3 and NOX5 drive differentiation of human oligodendrocytes. Front Cell Neurosci 10:1-17. https:// doi.org/10.3389/fncel.2016.00146

84. Baarine M, Andréoletti P, Athias A et al (2012) Evidence of oxidative stress in very long chain fatty acid-treated oligodendrocytes and potentialization of ROS production using RNA interference-directed knockdown of ABCD1 and ACOX1 peroxisomal proteins. Neuroscience 213:1-18. https://doi. org/10.1016/j.neuroscience.2012.03.058

85. Paintlia MK, Paintlia AS, Singh AK, Singh I (2011) Synergistic activity of interleukin-17 and tumor necrosis factor- $\alpha$ enhances oxidative stress-mediated oligodendrocyte apoptosis. J Neurochem 116:508-521. https://doi.org/10.111 1/j.1471-4159.2010.07136.x

86. Jana M, Pahan K (2005) Redox regulation of cytokine-mediated inhibition of myelin gene expression in human primary oligodendrocytes. Free Radic Biol Med 39:823-831. https://doi. org/10.1016/j.freeradbiomed.2005.05.014

87. Deng W, Wang H, Rosenberg PA et al (2004) Role of metabotropic glutamate receptors in oligodendrocyte excitotoxicity and oxidative stress. Proc Natl Acad Sci U S A 101:7751-7756. https ://doi.org/10.1073/pnas.0307850101

88. Schmitz T, Endesfelder S, Chew LJ et al (2012) Minocycline protects oligodendroglial precursor cells against injury caused by oxygen-glucose deprivation. J Neurosci Res 90:933-944. https:// doi.org/10.1002/jnr.22824

89. Back SA, Han BH, Luo NL et al (2002) Selective vulnerability of late oligodendrocyte progenitors to hypoxia-ischemia. J Neurosci 22:455-463. https://doi.org/10.1523/jneurosci.22-02-00455.2002

90. Kukley M, Capetillo-Zarate E, Dietrich D (2007) Vesicular glutamate release from axons in white matter. Nat Neurosci 10:311320. https://doi.org/10.1038/nn1850

91. Sakry D, Karram K, Trotter J (2011) Synapses between NG2 glia and neurons. J Anat 219:2-7. https://doi.org/10.111 1/j.1469-7580.2011.01359.x
92. Sánchez-Gómez MV, Alberdi E, Ibarretxe G et al (2003) Caspase-dependent and caspase-independent oligodendrocyte death mediated by AMPA and Kainate receptors. J Neurosci 23:95199528. https://doi.org/10.1523/jneurosci.23-29-09519.2003

93. Rosin C, Bates TE, Skaper SD (2004) Excitatory amino acid induced oligodendrocyte cell death in vitro: receptor-dependent and -independent mechanisms. J Neurochem 90:1173-1185. https://doi.org/10.1111/j.1471-4159.2004.02584.x

94. Cavaliere F, Urra O, Alberdi E, Matute C (2012) Oligodendrocyte differentiation from adult multipotent stem cells is modulated by glutamate. Cell Death Dis 3:e268-e268. https://doi. org/10.1038/cddis.2011.144

95. Cavaliere F, Benito-Muñoz M, Panicker M, Matute C (2013) NMDA modulates oligodendrocyte differentiation of subventricular zone cells through PKC activation. Front Cell Neurosci 7:1-7. https://doi.org/10.3389/fncel.2013.00261

96. Luyt K, Váradi A, Durant CF, Molnár E (2006) Oligodendroglial metabotropic glutamate receptors are developmentally regulated and involved in the prevention of apoptosis. J Neurochem 99:641-656. https://doi.org/10.1111/j.1471-4159.2006.04103.x

97. Wu Z, Du Y, Xue H et al (2012) Aluminum induces neurodegeneration and its toxicity arises from increased iron accumulation and reactive oxygen species (ROS) production. Neurobiol Aging 33:199.e1-199.e12. https://doi.org/10.1016/j.neurobiola ging.2010.06.018

98. Huang H, Chen J, Lu H et al (2017) Iron-induced generation of mitochondrial ROS depends on AMPK activity. Biometals 30:623-628. https://doi.org/10.1007/s10534-017-0023-0

99. Adam-Vizi V, Starkov AA (2010) Calcium and mitochondrial reactive oxygen species generation: How to read the facts. J Alzheimer's Dis 20:S413-S426. https://doi.org/10.3233/JAD-2010100465

100. Pfanner N, Warscheid B, Wiedemann N (2019) Mitochondrial proteins: from biogenesis to functional networks. Nat Rev Mol Cell Biol 20:267-284. https://doi.org/10.1038/s4158 0-018-0092-0

101. Su K, Bourdette D, Forte M (2013) Mitochondrial dysfunction and neurodegeneration in multiple sclerosis. Front Physiol 4:110. https://doi.org/10.3389/fphys.2013.00169

102. Mahad DJ, Ziabreva I, Campbell GR et al (2009) Mitochondrial changes within axons in multiple sclerosis. Brain 132:11611174. https://doi.org/10.1097/WCO.0b013e3283533a25

103. Andrews $\mathrm{H}$, White $\mathrm{K}$, Thomson $\mathrm{C}$ et al (2006) Increased axonal mitochondrial activity as an adaptation to myelin deficiency in the shiverer mouse. J Neurosci Res 83:1533-1539

104. Lowe AJ, Paquola C, Vos de Wael R et al (2019) Targeting age-related differences in brain and cognition with multimodal imaging and connectome topography profiling. Hum Brain Mapp 40:5213-5230. https://doi.org/10.1002/hbm.24767

105. Kausar S, Wang F, Cui H (2018) The role of mitochondria in reactive oxygen species generation and its implications for neurodegenerative diseases. Cells 7:274. https://doi.org/10.3390/cells 7120274

106. Li J, Baud O, Vartanian T et al (2005) Peroxynitrite generated by inducible nitric oxide synthase and NADPH oxidase mediates microglial toxicity to oligodendrocytes. Proc Natl Acad Sci U S A 102:9936-9941. https://doi.org/10.1073/pnas.0502552102

107. Van Horssen J, Witte ME, Schreibelt G, de Vries HE (2011) Radical changes in multiple sclerosis pathogenesis. Biochim Biophys Acta Mol Basis Dis 1812:141-150. https://doi.org/10.1016/j. bbadis.2010.06.011

108. Carlström KE, Ewing E, Granqvist M et al (2019) Therapeutic efficacy of dimethyl fumarate in relapsing-remitting multiple sclerosis associates with ROS pathway in monocytes. Nat Commun. https://doi.org/10.1038/s41467-019-11139-3 
109. Carlström KE, Zhu K, Ewing E et al (2020) Gsta4 controls apoptosis of differentiating adult oligodendrocytes during homeostasis and remyelination via the mitochondria-associated FasCasp8-Bid-axis. Nat Commun. https://doi.org/10.1038/s4146 7-020-17871-5

110. Hultqvist M, Bäcklund J, Bauer K et al (2007) Lack of reactive oxygen species breaks t cell tolerance to collagen type II and allows development of arthritis in mice. J Immunol 179:14311437. https://doi.org/10.4049/jimmunol.179.3.1431

111. Becanovic K, Jagodic M, Sheng JR et al (2006) Advanced intercross line mapping of Eae5 reveals Ncf-1 and CLDN4 as candidate genes for experimental autoimmune encephalomyelitis. J Immunol 176:6055-6064. https://doi.org/10.4049/jimmu nol.176.10.6055

112. Lassmann H, Van Horssen J (2011) The molecular basis of neurodegeneration in multiple sclerosis. FEBS Lett 585:3715-3723. https://doi.org/10.1016/j.febslet.2011.08.004

113. Fischer MT, Sharma R, Lim JL et al (2012) NADPH oxidase expression in active multiple sclerosis lesions in relation to oxidative tissue damage and mitochondrial injury. Brain 135:886899. https://doi.org/10.1093/brain/aws012

114. Howell OW, Rundle JL, Garg A et al (2010) Activated microglia mediate axoglial disruption that contributes to axonal injury in multiple sclerosis. J Neuropathol Exp Neurol 69:1017-1033. https://doi.org/10.1097/NEN.0b013e3181f3a5b1

115. Allen IV, McQuaid S, Mirakhur M, Nevin G (2001) Pathological abnormalities in the normal-appearing white matter in multiple sclerosis. Neurol Sci 22:141-144. https://doi.org/10.1007/s1007 20170012

116. van Horssen J, Singh S, van der Pol S et al (2012) Clusters of activated microglia in normal-appearing white matter show signs of innate immune activation. J Neuroinflammation 9:1-9. https ://doi.org/10.1186/1742-2094-9-156

117. Yirmiya R, Rimmerman N, Reshef R (2015) Depression as a microglial disease. Trends Neurosci 38:637-658. https://doi. org/10.1016/j.tins.2015.08.001

118. Monji A, Kato T, Kanba S (2009) Activated microglia. Psychiatry Clin Neurosci 63:257-265

119. Monji A, Kato TA, Mizoguchi Y et al (2013) Neuroinflammation in schizophrenia especially focused on the role of microglia. Prog Neuro-Psychopharmacol Biol Psychiatry 42:115-121. https ://doi.org/10.1016/j.pnpbp.2011.12.002

120. Block ML (2008) NADPH oxidase as a therapeutic target in Alzheimer's disease. BMC Neurosci 9:1-8. https://doi. org/10.1186/1471-2202-9-S2-S8

121. Wilkinson K, El Khoury J (2012) Microglial scavenger receptors and their roles in the pathogenesis of Alzheimer's disease. Int J Alzheimers Dis 2012:489456. https://doi. org/10.1155/2012/489456

122. Wu D-C, Teismann P, Tieu K et al (2003) NADPH oxidase mediates oxidative stress in the 1-methyl-4-phenyl-1,2,3,6-tetrahydropyridine model of Parkinson's disease. Proc Natl Acad Sci 100:6145-6150. https://doi.org/10.1073/pnas.0937239100

123. Lee JK, Tran T, Tansey MG (2009) Neuroinflammation in Parkinson's disease. J Neuroimmune Pharmacol 4:419-429. https:// doi.org/10.1007/s11481-009-9176-0

124. Zhao SC, Ma LS, Chu ZH et al (2017) Regulation of microglial activation in stroke. Acta Pharmacol Sin 38:445-458. https://doi. org/10.1038/aps.2016.162

125. Nellessen A, Nyamoya S, Zendedel A et al (2020) Nrf2 deficiency increases oligodendrocyte loss, demyelination, neuroinflammation and axonal damage in an MS animal model. Metab Brain Dis 35:353-362. https://doi.org/10.1007/s11011-01900488-z
126. Lim JL, van der Pol SMA, Baron W et al (2016) Protandim protects oligodendrocytes against an oxidative insult. Antioxidants 5:1-15. https://doi.org/10.3390/antiox5030030

127. Veiga S, Ly JL, Chan PH et al (2011) SOD1 overexpression improves features of the oligodendrocyte precursor response in vitro. Neurosci Lett 503:10-14. https://doi.org/10.1038/ jid.2014.371

128. Baud O, Haynes RF, Wang $\mathrm{H}$ et al (2004) Developmental upregulation of MnSOD in rat oligodendrocytes confers protection against oxidative injury. Eur J Neurosci 20:29-40. https://doi. org/10.1111/j.0953-816X.2004.03451.x

129. Adibhatla RM, Hatcher JF (2010) Lipid oxidation and peroxidation in CNS Health and disease: From molecular mechanisms to therapeutic opportunities. Antioxid Redox Signal 12:125-169. https://doi.org/10.1089/ars.2009.2668

130. Wetzels S, Wouters K, Schalkwijk CG et al (2017) Methylglyoxal-derived advanced glycation endproducts in multiple sclerosis. Int J Mol Sci 18:421. https://doi.org/10.3390/ijms1 8020421

131. Wetzels S, Wouters K, Miyata T et al (2018) Advanced glycation endproducts are increased in the animal model of multiple sclerosis but cannot be reduced by pyridoxamine treatment or glyoxalase 1 overexpression. Int J Mol Sci 19:1-12. https://doi. org/10.3390/ijms19051311

132. Mailleux J, Vanmierlo T, Bogie JFJ et al (2018) Active liver X receptor signaling in phagocytes in multiple sclerosis lesions. Mult Scler J 24:279-289. https://doi.org/10.1177/1352458517 696595

133. Sousa BC, Pitt AR, Spickett CM (2017) Chemistry and analysis of HNE and other prominent carbonyl-containing lipid oxidation compounds. Free Radic Biol Med 111:294-308. https://doi. org/10.1016/j.freeradbiomed.2017.02.003

134. Aldini G, Orioli M, Carini M (2011) Protein modification by acrolein: relevance to pathological conditions and inhibition by aldehyde sequestering agents. Mol Nutr Food Res 55:1301-1319. https://doi.org/10.1002/mnfr.201100182

135. Ayala A, Munoz MF, Arguelles S (2014) Lipid peroxidation: production, metabolism, and signaling mechanisms of malondialdehyde and 4-hydroxy-2-nonenal. Oxid Med Cell Longev. https ://doi.org/10.1007/978-3-211-33303-7_2

136. Dickinson BC, Chang CJ (2011) Chemistry and biology of reactive oxygen species in signaling or stress responses. Nat Chem Biol 7:504-511. https://doi.org/10.1038/nchembio.607

137. Riyi S, Rickett T, Sun W (2011) Acrolein-mediated injury in nervous system trauma and diseases. Mol Nutr Food Res 55:1320-1331. https://doi.org/10.1038/jid.2014.371

138. Leonarduzzi G, Robbesyn F, Poli G (2004) Signaling kinases modulated by 4-hydroxynonenal. Free Radic Biol Med 37:1694 1702. https://doi.org/10.1016/j.freeradbiomed.2004.08.027

139. Semchyshyn HM (2014) Reactive carbonyl species in vivo: generation and dual biological effects. Sci World J 2014:417842. https://doi.org/10.1155/2014/417842

140. Birben E, Sahiner UM, Sackesen C et al (2012) Oxidative stress and antioxidant defense. World Allergy Organ J 5:9-19. https:// doi.org/10.1128/9781555817558.ch19

141. Butts BD, Houde C, Mehmet H (2008) Maturation-dependent sensitivity of oligodendrocyte lineage cells to apoptosis: Implications for normal development and disease. Cell Death Differ 15:1178-1186. https://doi.org/10.1038/cdd.2008.70

142. Szebeni A, Szebeni K, DiPeri T et al (2014) Shortened telomere length in white matter oligodendrocytes in major depression: potential role of oxidative stress. Int J Neuropsychopharmacol 17:1579-1589. https://doi.org/10.1017/S1461145714000698

143. Kim GH, Kim JE, Rhie SJ, Yoon S (2015) The role of oxidative stress in neurodegenerative diseases. Exp Neurobiol 24:325. https ://doi.org/10.5607/en.2015.24.4.325 
144. Ott M, Gogvadze V, Orrenius S, Zhivotovsky B (2007) Mitochondria, oxidative stress and cell death. Apoptosis 12:913-922. https://doi.org/10.1007/s10495-007-0756-2

145. Baud O, Greene AE, Li J et al (2004) Glutathione peroxidase-catalase cooperativity is required for resistance to hydrogen peroxidase by mature rat oligodendrocytes. J Neurosci 24:1531-1540. https://doi.org/10.1523/JNEUROSCI.3989-03.2004

146. Forman HJ, Zhang H, Rinna A (2009) Glutathione: overview of its protective roles, measurement, and biosynthesis. Mol Aspects Med 30:1-12. https://doi.org/10.1016/j.mam.2008.08.006

147. Boulanger JJ, Messier C (2017) Doublecortin in oligodendrocyte precursor cells in the adult mouse brain. Front Neurosci 11:1-11. https://doi.org/10.3389/fnins.2017.00143

148. Tamura Y, Kataoka Y, Cui Y et al (2007) Intracellular translocation of glutathione S-transferase pi during oligodendrocyte differentiation in adult rat cerebral cortex in vivo. Neuroscience 148:535-540. https://doi.org/10.1016/j.neuroscien ce.2007.06.026

149. Gotts JE, Chesselet MF (2005) Migration and fate of newly born cells after focal cortical ischemia in adult rats. J Neurosci Res 80:160-171. https://doi.org/10.1002/jnr.20434

150. Back SA, Gan X, Li Y et al (1998) Maturation-dependent vulnerability of oligodendrocytes to oxidative stress-induced death caused by glutathione depletion. J Neurosci 18:6241-6253. https ://doi.org/10.1523/jneurosci.18-16-06241.1998

151. Juurlink BHJ, Thorburne SK, Hertz L (1998) Peroxide-scavenging deficit underlies oligodendrocyte susceptibility to oxidative stress. Glia 22:371-378. https://doi.org/10.1002/(SICI)10981136(199804)22:4\%3c371::AID-GLIA6\%3e3.0.CO;2-6

152. French HM, Reid M, Mamontov P et al (2009) Oxidative stress disrupts oligodendrocyte maturation. J Neurosci Res 87:30763087. https://doi.org/10.1002/jnr.22139

153. Fragoso G, Martínez-Bermúdez AK, Liu HN et al (2004) Developmental differences in $\mathrm{H}_{2} \mathrm{O}_{2}$-induced oligodendrocyte cell death: role of glutathione, mitogen-activated protein kinases and caspase 3. J Neurochem 90:392-404. https://doi.org/10.111 1/j.1471-4159.2004.02488.x

154. Schulz K, Vulpe CD, Harris LZ, David S (2011) Iron efflux from oligodendrocytes is differentially regulated in gray and white matter. J Neurosci 31:13301-13311. https://doi.org/10.1523/ JNEUROSCI.2838-11.2011

155. Henle ES, Han Z, Tang N et al (1999) Sequence-specific DNA cleavage by $\mathrm{Fe} 2+$-mediated fenton reactions has possible biological implications. J Biol Chem 274:962-971. https://doi. org/10.1074/jbc.274.2.962

156. Vomhof-DeKrey EE, Picklo MJ (2012) The Nrf2-antioxidant response element pathway: a target for regulating energy metabolism. J Nutr Biochem 23:1201-1206. https://doi.org/10.1016/j. jnutbio.2012.03.005

157. Silva MM, Rocha CRR, Kinker GS et al (2019) The balance between NRF2/GSH antioxidant mediated pathway and DNA repair modulates cisplatin resistance in lung cancer cells. Sci Rep 9:1-11. https://doi.org/10.1038/s41598-019-54065-6

158. van Horssen J, Drexhage JAR, Flor T et al (2010) Nrf2 and DJ1 are consistently upregulated in inflammatory multiple sclerosis lesions. Free Radic Biol Med 49:1283-1289. https://doi. org/10.1016/j.freeradbiomed.2010.07.013

159. Giacci M, Fitzgerald M (2018) Oligodendroglia are particularly vulnerable to oxidative damage after neurotrauma in vivo. J Exp Neurosci. https://doi.org/10.1177/1179069518810004

160. Haider L, Fischer MT, Frischer JM et al (2011) Oxidative damage in multiple sclerosis lesions. Brain 134:1914-1924. https://doi. org/10.1093/brain/awr128

161. van Horssen J, Schreibelt G, Drexhage J et al (2008) Severe oxidative damage in multiple sclerosis lesions coincides with enhanced antioxidant enzyme expression. Free Radic Biol
Med 45:1729-1737. https://doi.org/10.1016/j.freeradbio med.2008.09.023

162. Jorissen W, Wouters E, Bogie JF et al (2017) Relapsing-remitting multiple sclerosis patients display an altered lipoprotein profile with dysfunctional HDL. Sci Rep 7:1-14. https://doi. org/10.1038/srep43410

163. Giacci MK, Bartlett CA, Smith NM et al (2018) Oligodendroglia are particularly vulnerable to oxidative damage after neurotrauma in vivo. J Neurosci 38:6491-6504. https://doi.org/10.1523/ JNEUROSCI.1898-17.2018

164. Bernardo A, Greco A, Levi G, Minghetti L (2003) Differential lipid peroxidation, Mn superoxide, and bcl-2 expression contribute to the maturation-dependent vulnerability of oligodendrocytes to oxidative stress. J Neuropathol Exp Neurol 62:509-519. https://doi.org/10.1093/jnen/62.5.509

165. Barres BA, Raff MC (1994) Control of oligodendrocyte number in the developing rat optic nerve. Neuron 12:935-942. https ://doi.org/10.1016/0896-6273(94)90305-0

166. Trapp BD, Nishiyama A, Cheng D, Macklin W (1997) Differentiation and death of premyelinating oligodendrocytes in developing rodent brain. J Cell Biol 137:459-468. https://doi. org/10.1083/jcb.137.2.459

167. Sun LO, Mulinyawe SB, Collins HY et al (2018) Spatiotemporal control of CNS myelination by oligodendrocyte programmed cell death through the TFEB-PUMA axis. Cell 175:1811-1826. https://doi.org/10.1016/j.cell.2018.10.044. Spatiotemporal

168. Miyamoto N, Maki T, Pham LDD et al (2013) Oxidative stress interferes with white matter renewal after prolonged cerebral hypoperfusion in mice. Stroke 44:3516-3521. https://doi. org/10.1161/STROKEAHA.113.002813

169. Gard AL, Solodushko VG, Waeg G, Majic T (2001) 4-Hydroxynonenal, a lipid peroxidation byproduct of spinal cord injury, is cytotoxic for oligodendrocyte progenitors and inhibits their responsiveness to PDGF. Microsc Res Tech 52:709-718. https ://doi.org/10.1002/jemt.1055

170. Pavlacky J, Polak J (2020) Technical feasibility and physiological relevance of hypoxic cell culture models. Front Endocrinol (Lausanne) 11:1-15. https://doi.org/10.3389/fendo.2020.00057

171. Takase H, Liang AC, Miyamoto N et al (2018) Protective effects of a radical scavenger edaravone on oligodendrocyte precursor cells against oxidative stress. Neurosci Lett 668:120-125. https ://doi.org/10.1016/j.neulet.2018.01.018

172. Tse KH, Herrup K (2017) DNA damage in the oligodendrocyte lineage and its role in brain aging. Mech Ageing Dev 161:37-50. https://doi.org/10.1016/j.mad.2016.05.006

173. Warnock A, Toomey LM, Wright AJ et al (2020) Damage mechanisms to oligodendrocytes and white matter in central nervous system injury: the Australian context. J Neurotrauma 37:739_ 769. https://doi.org/10.1089/neu.2019.6890

174. Nissanka N, Moraes CT (2018) Mitochondrial DNA damage and reactive oxygen species in neurodegenerative disease. FEBS Lett 592:728-742. https://doi.org/10.1002/1873-3468.12956

175. Chatterjee N, Walker GC (2017) Mechanisms of DNA damage, repair, and mutagenesis. Environ Mol Mutagen 58:235-263. https://doi.org/10.1002/em.22087

176. Gentile F, Arcaro A, Pizzimenti S et al (2017) DNA damage by lipid peroxidation products: implications in cancer, inflammation and autoimmunity. AIMS Genet 4:103-137. https://doi. org/10.3934/genet.2017.2.103

177. Radak Z, Zhao Z, Goto S, Koltai E (2011) Age-associated neurodegeneration and oxidative damage to lipids, proteins and DNA. Mol Aspects Med 32:305-315. https://doi.org/10.1016/j. mam.2011.10.010 
178. Kim HS, Hromas R, Lee S-H (2013) Emerging features of DNA double-strand break repair in humans. In: New research directions in DNA repair. pp 187-211

179. Sharma V, Collins LB, Chen T et al (2016) Oxidative stress at low levels can induce clustered DNA lesions leading to NHEJ mediated mutations. Oncotarget 7:25377-25390

180. Madsen PM, Pinto M, Patel S et al (2017) Mitochondrial DNA double-strand breaks in oligodendrocytes cause demyelination, axonal injury, and CNS inflammation. J Neurosci 37:1018510199. https://doi.org/10.1523/JNEUROSCI.1378-17.2017

181. Pinto M, Moraes CT (2015) Mechanisms linking mtDNA damage and aging. Free Radic Biol Med 85:250-258. https://doi. org/10.1016/j.physbeh.2017.03.040

182. Migliore L, Coppedè F (2009) Environmental-induced oxidative stress in neurodegenerative disorders and aging. Mutat Res Genet Toxicol Environ Mutagen 674:73-84. https://doi.org/10.1016/j. mrgentox.2008.09.013

183. De Zio D, Bordi M, Cecconi F (2012) Oxidative DNA damage in neurons: Implication of $\mathrm{Ku}$ in neuronal homeostasis and survival. Int J Cell Biol. https://doi.org/10.1155/2012/752420

184. Hollensworth SB, Shen CC, Sim JE et al (2000) Glial cell typespecific responses to menadione-induced oxidative stress. Free Radic Biol Med 28:1161-1174. https://doi.org/10.1016/S0891 $-5849(00) 00214-8$

185. Helena JM, Joubert AM, Grobbelaar S et al (2018) Deoxyribonucleic acid damage and repair: capitalizing on our understanding of the mechanisms of maintaining genomic integrity for therapeutic purposes. Int J Mol Sci. https://doi.org/10.3390/ ijms 19041148

186. Van Houten B, Santa-Gonzalez GA, Camargo M (2018) DNA repair after oxidative stress: current challenges. Curr Opin Toxicol 7:9-16. https://doi.org/10.1016/j.cotox.2017.10.009

187. Druzhyna NM, Hollensworth SB, Kelley MR et al (2003) Targeting human 8-oxoguanine glycosylase to mitochondria of oligodendrocytes protects against menadione-induced oxidative stress. Glia 42:370-378. https://doi.org/10.1002/glia.10230

188. Spitzer SO, Sitnikov S, Kamen Y et al (2019) Oligodendrocyte progenitor cells become regionally diverse and heterogeneous with age. Neuron 101:459-471.e5. https://doi.org/10.1016/j. neuron.2018.12.020

189. Lü HZ, Wang YX, Li Y et al (2008) Proliferation and differentiation of oligodendrocyte progenitor cells induced from rat embryonic neural precursor cells followed by flow cytometry. Cytom Part A 73:754-760. https://doi.org/10.1002/cyto.a.20577

190. Lieber MR (2010) The mechanism of double-strand DNA break repair by the nonhomologous DNA end-joining pathway. Annu Rev Biochem 79:181-211. https://doi.org/10.1146/annurev.bioch em.052308.093131

191. Liu B, Chen X, Wang ZQ, Tong WM (2014) Nbn gene inactivation in the CNS of mouse inhibits the myelinating ability of the mature cortical oligodendrocytes. Glia 62:133-144. https://doi. org/10.1002/glia.22593

192. Liu B, Chen X, Wang ZQ, Tong WM (2014) DNA damage and oxidative injury are associated with hypomyelination in the corpus callosum of newborn NbnCNS-del mice. J Neurosci Res 92:254-266. https://doi.org/10.1002/jnr.23313

193. Arter J, Wegner M (2015) Transcription factors Sox 10 and Sox 2 functionally interact with positive transcription elongation factor b in Schwann cells. J Neurochem 132:384-393. https://doi. org/10.1111/jnc. 13013

194. Bannister AJ, Kouzarides T (2011) Regulation of chromatin by histone modifications. Cell Res 21:381-395. https://doi. org/10.1038/cr.2011.22

195. Eberharter A, Becker PB (2002) Histone acetylation: a switch between repressive and permissive chromatin. Second in review on chromatin dynamics. EMBO Rep 3:224-229. https://doi. org/10.1093/embo-reports/kvf053

196. Kreuz S, Fischle W (2016) Oxidative stress signaling to chromatin in health and disease. Epigenomics 8:843-862

197. Ito K, Hanazawa T, Tomita K et al (2004) Oxidative stress reduces histone deacetylase 2 activity and enhances IL-8 gene expression: role of tyrosine nitration. Biochem Biophys Res Commun 315:240-245. https://doi.org/10.1016/j. bbrc.2004.01.046

198. Doyle K, Fitzpatrick FA (2010) Redox signaling, alkylation (carbonylation) of conserved cysteines inactivates class I histone deacetylases 1,2, and 3 and antagonizes their transcriptional repressor function. J Biol Chem 285:17417-17424. https://doi. org/10.1074/jbc.M109.089250

199. Ye F, Chen Y, Hoang T et al (2009) HDAC1 and HDAC2 regulate oligodendrocyte differentiation by disrupting the B-catenin-TCF interaction. Nat Neurosci 12:829-838. https:// doi.org/10.1038/nn.2333

200. Conway GD, O'Bara MA, Vedia BH et al (2012) Histone deacetylase activity is required for human oligodendrocyte progenitor differentiation. Glia 60:1944-1953. https://doi. org/10.1002/glia.22410

201. Shen S, Li J, Casaccia-Bonnefil P (2005) Histone modifications affect timing of oligodendrocyte progenitor differentiation in the developing rat brain. J Cell Biol 169:577-589. https://doi. org/10.1083/jcb.200412101

202. Shen S, Sandoval J, Swiss VA et al (2008) Age-dependent epigenetic control of differentiation inhibitors is critical for remyelination efficiency. Nat Neurosci 11:1024-1034. https:// doi.org/10.1038/nn.2172

203. Lister R, Pelizzola M, Dowen RH et al (2009) Human DNA methylomes at base resolution show widespread epigenomic differences. Nature 462:315-322. https://doi.org/10.1038/natur $\mathrm{e} 08514$

204. Kim M, Costello J (2017) DNA methylation: An epigenetic mark of cellular memory. Exp Mol Med. https://doi. org/10.1038/emm.2017.10

205. Fuks F, Hurd PJ, Wolf D et al (2003) The methyl-CpG-binding protein MeCP2 links DNA methylation to histone methylation. J Biol Chem 278:4035-4040. https://doi.org/10.1074/jbc. M210256200

206. Moyon S, Casaccia P (2017) DNA methylation in oligodendroglial cells during developmental myelination and in disease. Neurogenesis 4:e1270381. https://doi.org/10.1080/23262 133.2016.1270381

207. Lewandowska J, Bartoszek A (2011) DNA methylation in cancer development, diagnosis and therapy-multiple opportunities for genotoxic agents to act as methylome disruptors or remediators. Mutagenesis 26:475-487. https://doi.org/10.1093/ mutage/ger019

208. Kietzmann T, Petry A, Shvetsova A et al (2017) The epigenetic landscape related to reactive oxygen species formation in the cardiovascular system. Br J Pharmacol 174:1533-1554. https ://doi.org/10.1111/bph.13792

209. Wu Q, Ni X (2015) ROS-mediated DNA methylation pattern alterations in carcinogenesis. Curr Drug Targets 16:13-19. https://doi.org/10.2174/1389450116666150113121054

210. Guillaumet-Adkins A, Yañez Y, Peris-Diaz MD et al (2017) Epigenetics and oxidative stress in aging. Oxid Med Cell Longev. https://doi.org/10.1155/2017/9175806

211. Zhou J, Wu YC, Jun XB et al (2019) Age-related changes in the global DNA methylation profile of oligodendrocyte progenitor cells derived from rat spinal cords. Curr Med Sci 39:67-74. https://doi.org/10.1007/s11596-019-2001-y

212. Moyon S, Huynh JL, Dutta D et al (2017) Functional characterization of DNA methylation in the oligodendrocyte 
lineage. Cell Rep 15:748-760. https://doi.org/10.1016/j.physb eh.2017.03.040

213. Moyon S, Ma D, Huynh JL et al (2017) Efficient remyelination requires DNA methylation. eNeuro 4:1-12. https://doi. org/10.1523/ENEURO.0336-16.2017

214. Zhao X, Dai J, Ma Y et al (2014) Dynamics of ten-eleven translocation hydroxylase family proteins and 5-hydroxymethylcytosine in oligodendrocyte differentiation. Glia 62:914-926. https://doi. org/10.1002/glia.22649

215. Sayed D, Abdellatif M (2011) Micrornas in development and disease. Physiol Rev 91:827-887. https://doi.org/10.1152/physr ev.00006.2010

216. Rodriguez A, Griffiths-Jones S, Ashurst JL, Bradley A (2004) Identification of mammalian microRNA host genes and transcription units. Genome Res 14:1902-1910. https://doi.org/10.1101/ gr.2722704

217. Konovalova J, Gerasymchuk D, Parkkinen I et al (2019) Interplay between microRNAs and oxidative stress in neurodegenerative diseases. Int J Mol Sci. https://doi.org/10.3390/ijms20236055

218. Engedal N, Žerovnik E, Rudov A et al (2018) From oxidative stress damage to pathways, networks, and autophagy via microRNAs. Oxid Med Cell Longev. https://doi.org/10.1155/2018/49683 21

219. Babu KR, Tay Y (2019) The Yin-Yang regulation of reactive oxygen species and microRNAs in cancer. Int J Mol Sci. https:// doi.org/10.3390/ijms20215335

220. Dugas JC, Cuellar TL, Scholze A et al (2010) Dicer1 and miR219 are required for normal oligodendrocyte differentiation and myelination. Neuron 65:597-611. https://doi.org/10.1161/ CIRCULATIONAHA.110.956839

221. Junker A, Krumbholz M, Eisele S et al (2009) MicroRNA profiling of multiple sclerosis lesions identifies modulators of the regulatory protein CD47. Brain 132:3342-3352. https://doi. org/10.1093/brain/awp300

222. Regev K, Paul A, Healy B et al (2016) Comprehensive evaluation of serum microRNAs as biomarkers in multiple sclerosis. Neurol Neuroimmunol NeuroInflamm 3:1-8. https://doi.org/10.1212/ NXI.0000000000000267

223. Tripathi A, Volsko C, Garcia JP et al (2019) Oligodendrocyte intrinsic miR-27a controls myelination and remyelination. Cell Rep 29:904-919.e9. https://doi.org/10.1016/j.celrep.2019.09.020

224. Indo HP, Davidson M, Yen HC et al (2007) Evidence of ROS generation by mitochondria in cells with impaired electron transport chain and mitochondrial DNA damage. Mitochondrion 7:106-118. https://doi.org/10.1016/j.mito.2006.11.026

225. Hiona A, Leeuwenburgh C (2008) The role of mitochondrial DNA mutations in aging and sarcopenia. Exp Gerontol 43:24-33

226. Aufschnaiter A, Kohler V, Diessl J et al (2017) Mitochondrial lipids in neurodegeneration. Cell Tissue Res 367:125-140. https ://doi.org/10.1007/s00441-016-2463-1

227. Lin TM, Beal MF (2006) Mitochondrial dysfunction and oxidative stress in neurodegenerative diseases. Nature 443:787-795

228. Lin TK, Hughes G, Muratovska A et al (2002) Specific modification of mitochondrial protein thiols in response to oxidative stress. A proteomics approach. J Biol Chem 277:17048-17056. https://doi.org/10.1074/jbc.M110797200

229. Xiao M, Zhong H, Xia L et al (2017) Pathophysiology of mitochondrial lipid oxidation: role of 4-hydroxynonenal (4-HNE) and other bioactive lipids in mitochondria. Free Radic Biol Med 111:316-327. https://doi.org/10.1016/j.freeradbio med.2017.04.363

230. Ryan K, Backos DS, Reigan P, Patel M (2012) Post-translational oxidative modification and inactivation of mitochondrial complex I in epileptogenesis. J Neurosci 32:11250-11258. https:// doi.org/10.1523/JNEUROSCI.0907-12.2012
231. Bautista J, Corpas R, Ramos R et al (2000) Brain mitochondrial complex I inactivation by oxidative modification. Biochem Biophys Res Commun 275:890-894. https://doi.org/10.1006/ bbrc. 2000.3388

232. Liessem-Schmitz A, Teske N, Scheld M et al (2018) Nrf2 signaling in sodium azide-treated oligodendrocytes restores mitochondrial functions. J Mol Neurosci 66:229-237. https://doi. org/10.1007/s12031-018-1159-2

233. Díaz-Castro B, Pardal R, García-Flores P et al (2015) Resistance of glia-like central and peripheral neural stem cells to genetically induced mitochondrial dysfunction-differential effects on neurogenesis. EMBO Rep 16:1511-1519. https://doi.org/10.15252/ embr.201540982

234. Herrero M, Mandelboum S, Elroy-Stein O (2019) eIF2B mutations cause mitochondrial malfunction in oligodendrocytes. NeuroMol Med 21:303-313. https://doi.org/10.1007/s1201 7-019-08551-9

235. Finck BN, Kelly DP (2006) PGC-1 coactivators: inducible regulators of energy metabolism in health and disease find the latest version : review series PGC-1 coactivators : inducible regulators of energy metabolism in health and disease. J Clin Invest 116:615-622. https://doi.org/10.1172/JCI27794.PGC-1

236. Jensen SK, Michaels NJ, Ilyntskyy S et al (2018) Multimodal enhancement of remyelination by exercise with a pivotal role for oligodendroglial PGC1 $\alpha$. Cell Rep 24:3167-3179. https:// doi.org/10.1016/j.celrep.2018.08.060

237. Xiang Z, Valenza M, Cui L et al (2011) Peroxisome-proliferator-activated receptor gamma coactivator $1 \alpha$ contributes to dysmyelination in experimental models of Huntington's disease. J Neurosci 31:9544-9553. https://doi.org/10.1523/JNEUR OSCI.1291-11.2011

238. Camacho A, Huang JK, Delint-Ramirez I et al (2013) Peroxisome proliferator-activated receptor gamma-coactivator-1 alpha coordinates sphingolipid metabolism, lipid raft composition and myelin protein synthesis. Eur J Neurosci 38:2672-2683. https:// doi.org/10.1111/ejn.12281

239. Viader A, Sasaki Y, Kim S et al (2013) Aberrant Schwann cell lipid metabolism linked to mitochondrial deficits leads to axon degeneration and neuropathy. Neuron 77:886-898. https://doi. org/10.1038/jid.2014.371

240. Viader A, Golden JP, Baloh RH et al (2011) Schwann cell mitochondrial metabolism supports long-term axonal survival and peripheral nerve function. J Neurosci 31:10128-10140. https:// doi.org/10.1523/JNEUROSCI.0884-11.2011

241. Paintlia AS, Paintlia MK, Singh AK, Singh I (2013) Modulation of rho-rock signaling pathway protects oligodendrocytes against cytokine toxicity via PPAR- $\alpha$-dependent mechanism. Glia 61:1500-1517. https://doi.org/10.1002/glia.22537

242. Bernardo A, Bianchi D, Magnaghi V, Minghetti L (2009) Peroxisome proliferator-activated receptor- $\gamma$ agonists promote differentiation and antioxidant defenses of oligodendrocyte progenitor cells. J Neuropathol Exp Neurol 68:797-808. https:// doi.org/10.1097/NEN.0b013e3181aba2c1

243. De Nuccio C, Bernardo A, Cruciani C et al (2015) Peroxisome proliferator activated receptor- $\gamma$ agonists protect oligodendrocyte progenitors against tumor necrosis factor-alpha-induced damage: effects on mitochondrial functions and differentiation. Exp Neurol 271:506-514. https://doi.org/10.1016/j.expne urol.2015.07.014

244. Almad A, McTigue DM (2010) Chronic expression of PPAR- $\delta$ by oligodendrocyte lineage cells in the injured rat spinal cord. J Comp Neurol 518:785-799. https://doi.org/10.1002/cne.22242

245. Saluja I, Granneman JG, Skoff RP (2001) PPAR $\delta$ agonists stimulate oligodendrocyte differentiation in tissue culture. Glia 33:191-204. https://doi.org/10.1002/1098-1136(20010 3)33:3\%3c191::AID-GLIA1018\%3e3.0.CO;2-M 
246. De Nuccio C, Bernardo A, De Simone R et al (2011) Peroxisome proliferator-activated receptor $\gamma$ agonists accelerate oligodendrocyte maturation and influence mitochondrial functions and oscillatory Ca2+ waves. J Neuropathol Exp Neurol 70:900-912. https ://doi.org/10.1097/NEN.0b013e3182309ab1

247. Roy A, Jana M, Corbett GT et al (2013) Regulation of CREB and hippocampal plasticity-related genes by peroxisome proliferator-activated receptor $\alpha$. Cell Rep 4:724-737. https://doi. org/10.1016/j.celrep.2013.07.028.Regulation

248. Zhang Y, Li X, Ciric B et al (2020) A dual effect of ursolic acid to the treatment of multiple sclerosis through both immunomodulation and direct remyelination. Proc Natl Acad Sci 117:90829093. https://doi.org/10.1073/pnas.2000208117

249. Hinchy EC, Gruszczyk AV, Willows R et al (2018) Mitochondriaderived ROS activate AMP-activated protein kinase (AMPK) indirectly. J Biol Chem. https://doi.org/10.1074/jbc.RA118 .002579

250. Cardaci S, Filomeni G, Ciriolo MR (2012) Redox implications of AMPK-mediated signal transduction beyond energetic clues. J Cell Sci 125:2115-2125. https://doi.org/10.1242/jcs.095216

251. Largani SHH, Borhani-Haghighi M, Pasbakhsh P et al (2019) Oligoprotective effect of metformin through the AMPK-dependent on restoration of mitochondrial hemostasis in the cuprizoneinduced multiple sclerosis model. J Mol Histol 50:263-271. https ://doi.org/10.1007/s10735-019-09824-0

252. Chew LJ, Coley W, Cheng Y, Gallo V (2010) Mechanisms of regulation of oligodendrocyte development by p38 mitogenactivated protein kinase. J Neurosci 30:11011-11027. https:// doi.org/10.1523/JNEUROSCI.2546-10.2010

253. Haines JD, Fulton DL, Richard S, Almazan G (2015) P38 mitogen-activated protein kinase pathway regulates genes during proliferation and differentiation in oligodendrocytes. PLoS ONE 10:1-19. https://doi.org/10.1371/journal.pone.0145843

254. Fyffe-Maricich SL, Karlo JC, Landreth GE, Miller RH (2011) The ERK2 mitogen-activated protein kinase regulates the timing of oligodendrocyte differentiation. J Neurosci 31:843-850. https ://doi.org/10.1523/JNEUROSCI.3239-10.2011

255. Ishii A, Furusho M, Macklin W, Bansal R (2019) Independent and cooperative roles of the Mek/ERK1/2-MAPK and PI3K/Akt/ mTOR pathways during developmental myelination and in adulthood. Glia 67:1277-1295. https://doi.org/10.1002/glia.23602

256. Ishii A, Furusho M, Bansal R (2013) Sustained activation of ERK1/2 MAPK in oligodendrocytes and schwann cells enhances myelin growth and stimulates oligodendrocyte progenitor expansion. J Neurosci 33:175-186. https://doi.org/10.1523/JNEUR OSCI.4403-12.2013

257. Bhat NR, Zhang P (1999) Hydrogen peroxide activation of multiple mitogen-activated protein kinases in an oligodendrocyte cell line: Role of extracellular signal-regulated kinase in hydrogen peroxide-induced cell death. J Neurochem 72:112-119. https:// doi.org/10.1046/j.1471-4159.1999.0720112.x

258. Bonora M, De Marchi E, Patergnani S et al (2014) Tumor necrosis factor- $\alpha$ impairs oligodendroglial differentiation through a mitochondria-dependent process. Cell Death Differ 21:11981208. https://doi.org/10.1038/cdd.2014.35

259. Oh J, Lee YD, Wagers AJ (2014) Stem cell aging: mechanisms, regulators and therapeutic opportunities. Nat Med 20:870-880. https://doi.org/10.1038/nm.3651

260. Owen JB, Sultana R, Aluise CD et al (2010) Oxidative modification to LDL receptor-related protein 1 in hippocampus from subjects with Alzheimer disease: Implications for $A \beta$ accumulation in AD brain. Free Radic Biol Med 49:1798-1803. https:// doi.org/10.1016/j.freeradbiomed.2010.09.013

261. Lin J-P, Mironova YA, Shrager P, Giger RJ (2017) LRP1 regulates peroxisome biogenesis and cholesterol homeostasis in oligodendrocytes and is required for proper CNS myelin development and repair. eLife 6:e30498. https://doi.org/10.7554/eLife .30498

262. Shao D, Oka S, Liu T et al (2014) A redox-dependent mechanism for regulation of AMPK activation by thioredoxin1 during energy starvation. Cell Metab 19:232-245. https://doi.org/10.1016/j. cmet.2013.12.013.A

263. Reznick RM, Zong H, Li J et al (2007) Aging-associated reductions in AMP-activated protein kinase activity and mitochondrial biogenesis. Cell Metab 5:151-156. https://doi.org/10.1016/j. cmet.2007.01.008

264. Siddiqui A, Chinta SJ, Mallajosyula JK et al (2012) Selective binding of nuclear alpha-synuclein to the PGC1alpha promoter under conditions of oxidative stress may contribute to losses in mitochondrial function: implications for Parkinson's disease. Free Radic Biol Med 53:993-1003. https://doi.org/10.1016/j. freeradbiomed.2012.05.024

265. Weng Q, Wang J, Wang J et al (2017) Folate metabolism regulates oligodendrocyte survival and differentiation by modulating AMPK $\alpha$ activity. Sci Rep 7:1-13. https://doi.org/10.1038/s4159 8-017-01732-1

266. Zhang X, Song Y, Feng M et al (2015) Thyroid-stimulating hormone decreases HMG-CoA reductase phosphorylation via AMPactivated protein kinase in the liver. J Lipid Res 56:963-971. https://doi.org/10.1194/jlr.M047654

267. Wang Q, Liu S, Zhai A et al (2018) AMPK-mediated regulation of lipid metabolism by phosphorylation. Biol Pharm Bull 41:985-993. https://doi.org/10.1248/bpb.b17-00724

268. Monnerie H, Romer M, Jensen BK et al (2017) Reduced sterol regulatory element-binding protein (SREBP) processing through site-1 protease (S1P) inhibition alters oligodendrocyte differentiation in vitro. J Neurochem 140:53-67. https://doi.org/10.1111/ jnc. 13721

269. Morita M, Gravel SP, Hulea L et al (2015) MTOR coordinates protein synthesis, mitochondrial activity. Cell Cycle 14:473-480. https://doi.org/10.4161/15384101.2014.991572

270. Wood TL, Bercury KK, Cifelli SE et al (2013) mTOR: A link from the extracellular milieu to transcriptional regulation of oligodendrocyte development. ASN Neuro 5:63-79. https://doi. org/10.1042/AN20120092

271. Witte ME, Nijland PG, Drexhage JAR et al (2013) Reduced expression of PGC- $1 \alpha$ partly underlies mitochondrial changes and correlates with neuronal loss in multiple sclerosis cortex. Acta Neuropathol 125:231-243. https://doi.org/10.1007/s0040 1-012-1052-y

272. Shaughnessy DT, McAllister K, Worth L et al (2015) Mitochondria, energetics, epigenetics, and cellular responses to stress. Environ Health Perspect 122:1271-1278. https://doi. org/10.1289/ehp. 1408418

273. Santiago A, Soares LM, Schepers M et al (2018) Roflumilast promotes memory recovery and attenuates white matter injury in aged rats subjected to chronic cerebral hypoperfusion. Neuropharmacology 138:360-370. https://doi.org/10.1016/j.neuro pharm.2018.06.019

274. Schepers M, Tiane A, Paes D et al (2019) Targeting phosphodiesterases-towards a tailor-made approach in multiple sclerosis treatment. Front Immunol 10:1727. https://doi.org/10.3389/ fimmu.2019.01727

275. Colzani M, De Maddis D, Casali G et al (2016) Reactivity, selectivity, and reaction mechanisms of aminoguanidine, hydralazine, pyridoxamine, and carnosine as sequestering agents of reactive carbonyl species: a comparative study. ChemMedChem 11:17781789. https://doi.org/10.1002/cmdc.201500552 
276. Tardiolo G, Bramanti P, Mazzon E (2018) Overview on the effects of $N$-acetylcysteine in neurodegenerative diseases. Molecules. https://doi.org/10.3390/molecules23123305

277. Couto JP, Moreira R (2018) Oral N-acetylcysteine in the treatment of obsessive-compulsive disorder: a systematic review of the clinical evidence. Prog Neuro-Psychopharmacol Biol Psychiatry 86:245-254. https://doi.org/10.1016/j.pnpbp.2018.06.005

278. Fernandes BS, Dean OM, Dodd S et al (2016) N-acetylcysteine in depressive symptoms and functionality: a systematic review and meta-analysis. J Clin Psychiatry 77:e457-e466. https://doi. org/10.4088/JCP.15r09984

279. Paintlia MK, Paintlia AS, Barbosa E et al (2004) N-acetylcysteine prevents endotoxin-induced degeneration of oligodendrocyte progenitors and hypomyelination in developing rat brain. J Neurosci Res 78:347-361. https://doi.org/10.1002/jnr.20261

280. Cammer W (2002) Protection of cultured oligodendrocytes against tumor necrosis factor- $\alpha$ by the antioxidants coenzyme Q10 and $N$-acetyl cysteine. Brain Res Bull 58:587-592. https:// doi.org/10.1016/S0361-9230(02)00830-4

281. Paintlia MK, Paintlia AS, Khan M et al (2008) Modulation of peroxisome proliferator-activated receptor- $\alpha$ activity by $N$-acetyl cysteine attenuates inhibition of oligodendrocyte development in lipopolysaccharide stimulated mixed glial cultures. J Neurochem 105:956-970. https://doi.org/10.1111/j.1471-4159.2007.05199.x

282. Zhang Y, Chen K, Sloan SA et al (2014) An RNA-sequencing transcriptome and splicing database of glia, neurons, and vascular cells of the cerebral cortex. J Neurosci 34:11929-11947. https ://doi.org/10.1523/JNEUROSCI.1860-14.2014

283. Delgado-Acevedo C, Estay SF, Radke AK et al (2019) Behavioral and synaptic alterations relevant to obsessive-compulsive disorder in mice with increased EAAT3 expression. Neuropsychopharmacology 44:1163-1173. https://doi.org/10.1038/s4138 6-018-0302-7

284. Huang H, Taraboletti A, Shriver LP (2015) Dimethyl fumarate modulates antioxidant and lipid metabolism in oligodendrocytes. Redox Biol 5:169-175. https://doi.org/10.1016/j.redox .2015.04.011

285. Scannevin RH, Chollate S, Jung MY et al (2012) Fumarates promote cytoprotection of central nervous system cells against oxidative stress via the nuclear factor (erythroid-derived 2)-like 2 pathway. J Pharmacol Exp Ther 341:274-284. https://doi. org/10.1124/jpet.111.190132

286. Nijland PG, Witte ME, van het Hof B et al (2014) Astroglial PGC-1alpha increases mitochondrial antioxidant capacity and suppresses inflammation: Implications for multiple sclerosis. Acta Neuropathol Commun 2:1-13. https://doi.org/10.1186/ s40478-014-0170-2

287. Sghaier R, Zarrouk A, Nury T et al (2019) Biotin attenuation of oxidative stress, mitochondrial dysfunction, lipid metabolism alteration and $7 \beta$-hydroxycholesterol-induced cell death in $158 \mathrm{~N}$ murine oligodendrocytes. Free Radic Res 53:535-561. https:// doi.org/10.1080/10715762.2019.1612891

288. Sedel F, Bernard D, Mock DM, Tourbah A (2016) Targeting demyelination and virtual hypoxia with high-dose biotin as a treatment for progressive multiple sclerosis. Neuropharmacology 110:644-653. https://doi.org/10.1016/j.neuropharm.2015.08.028

289. Gioia U, Francia S, Cabrini M et al (2019) Pharmacological boost of DNA damage response and repair by enhanced biogenesis of DNA damage response RNAs. Sci Rep 9:1-15. https://doi. org/10.1038/s41598-019-42892-6

290. Roberti A, Valdes AF, Torrecillas R et al (2019) Epigenetics in cancer therapy and nanomedicine. Clin Epigenet 11:1-18. https ://doi.org/10.1186/s13148-019-0675-4

291. Pao PC, Patnaik D, Watson LA et al (2020) HDAC1 modulates OGG1-initiated oxidative DNA damage repair in the aging brain and Alzheimer's disease. Nat Commun. https://doi.org/10.1038/ s41467-020-16361-y

292. Rachek LI, Grishko VI, Musiyenko SI et al (2002) Conditional targeting of the DNA repair enzyme hOGG1 into mitochondria. J Biol Chem 277:44932-44937. https://doi.org/10.1074/jbc. M208770200

Publisher's Note Springer Nature remains neutral with regard to jurisdictional claims in published maps and institutional affiliations. 